\section{Prediction of annual runoff in ungauged basins}

Contributors: T. A. McMahon," G. Laaha, J. Parajka, Contributors. T. A. Mc Maviije, M. Sivalan, J. Szolga) M. C. Peel, H. H. G. Siglione, R. A. Woods and D. Yang

S. E. Thompson, A. Viglione, R. A. Wods and D. Yang

Mean annual runoff is the average of annual runoff values estimated over many years. Is inter-annual variability is usually quantified in terms of the staff It can also be (or coefficient of variation) of annual runorf. Il can also be expressed in terms of the growth-curve (i.e., cumn see frequency distribution scaled by the long-e Chapter 9 for examples in the context of annual runoff. Although conmonly the (i.e., stationary in the statistical sense) bor the mer inter-annual variability of runoff may change over a result of long-term (natural) changes in clinge, cactment characteristics or anthropogenic factors. For example, Kuczera (1987) and Vertessy et al. (2001) descibe interdecadal to century-scale changes in runoff due to nonstationary water use of Mountain Ash ( $E$. stationa wow w following disturbance by fire.

nary design of water Annual runoff is used in the preliminary 2005) involved in supply systems (McMahon and Adeloye, allocating water for the environment, inigation, indury human consumption, hydropower, navigation, recreation hund and management. Techniques for preliminary and carchsociated with the sizing of water supply systems anting the annual yield from an existing system are or estable and were reviewed by McMahon et al. (2007a) avallable database of annual (and monthly) runoff. using a gan annual runoff, its variability and autoEstmelation are needed for many of these techniques. An correlatis is also used to assess climate change impacts on runof is alros (Arnell, 1999; Milly et al.., 2005) and land water use change in 2011). Other uses of annual runoff include Komats with respect to the global water crisis, water and analyses wit sobal food production, and understand sustainabity water cycle (e g. Vörösmarty et al., 2010).

iability are importAnnual un the surface water balance of a landscape. ant diagn a large spatial scales. Annual runoff varialy especially at large spnatures of runoff variability (Sivapalia is one of several signaturs 2007), the others being 2005, Wagene (see Chapter 6), the flow duraton $c$ regime curve (see Chapter 6), the flow dusion cind
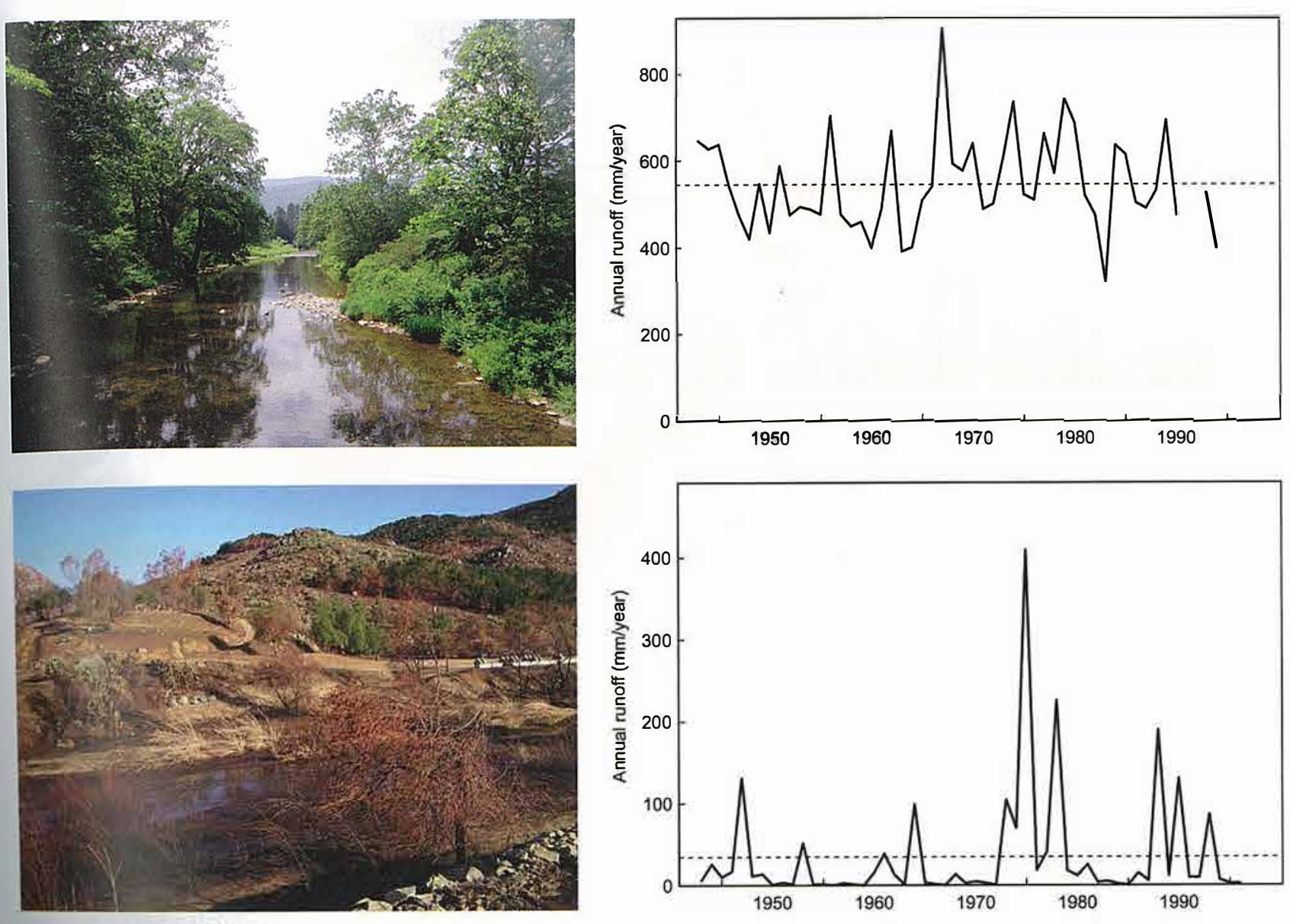

Figure 5.1. Annual runoff in two US catchments: (top)

(see Chapter 7) and the flood frequency curve (see Chapter 9). Understanding the drivers and causes of annual runoff variability can improve our ablity to predict runoff variability at all time scales, including the complete runoff hydrograph (see Chapter 10). These signatures can assist in the development and parmeterisation of rainfall-runoff models (Farmer et al, 2003. Bárdossy, 2007). Mean annual runoff is also often used as an index to nomalise other signatures as part of regionalisation studies. For example, it is common to estimate nomalised flow duration curves for ungauged catchments, where the normatation is with respect to the ment deloye. 2005) or the median iunf (Best et at. 2003).

5.2 Annual runoff: processes and similarity

Figure 5.1 presents examples of mean annual runoff and annual runoff variability from two catch sre localed in the USA, but in two contrasting of similar relatively wet West Virginia and the dry Southe wia. The pictures are representative of the landscape

vegetation for the two catchments. The catchment in West Virginia (Figure 5.1, top row) has much higher mean annua runoff (close to $1000 \mathrm{~mm} / \mathrm{yr}$ ) with moderate inter-annual variability (range of about $\pm 300 \mathrm{~mm}$ ). The catchment in California (Figure 5.1, bottom row) has instead a very low mean annual runoff (below $50 \mathrm{~mm} / \mathrm{yr}$ ) but high variability between years (close to zero and/or exceeding three times the mean). It is interesting to explore why there is much less runoff but with greater variability in the Calitofnian river compared to that in West Virginia. Predicting annual runoff in ungauged basins is the starting point for predicting all other runoff signatures in this book. Therefore, insight into the causal processes leading to the long-term mean and variability, and how similarity and dissimilarity between catchents is essential.

This chapter begins by discussing the process controls extent of annual runoff variabity, how these are governed by the combined effects of climate soils and vegettion (including land cover change). Undersals af controls is used to formulate a list of similarity indices tha 
72

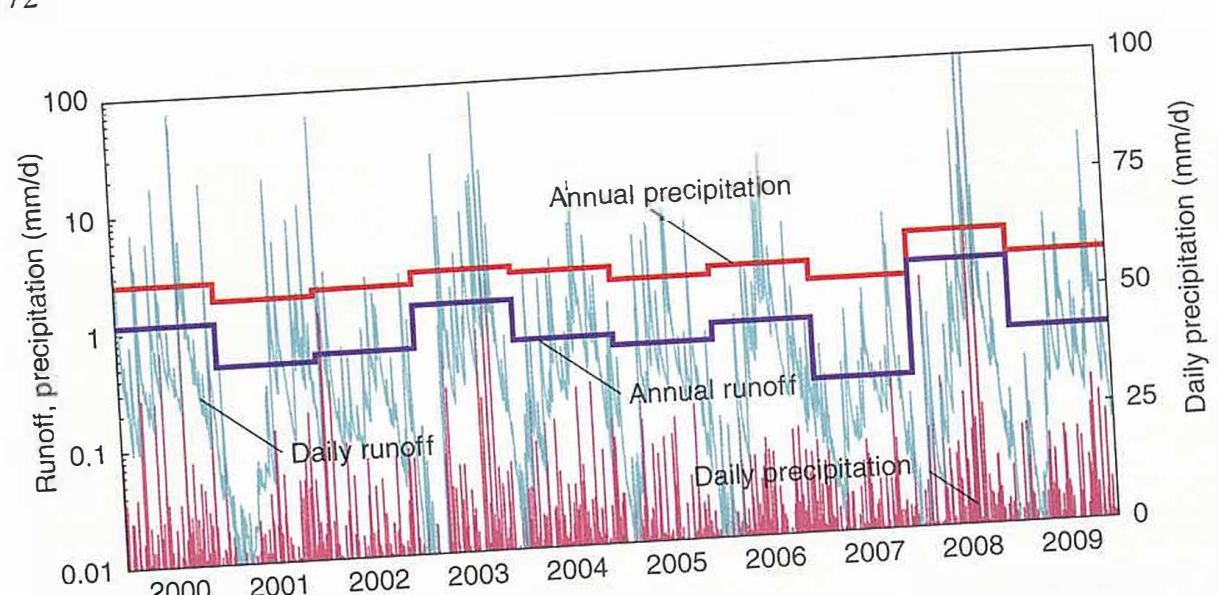

5.2. Daily precipitation and runoff time series, with the annual series superimposed as thick lines. Here, the seasonal cycle is driven mainly by potential evapora River at Cheddar Valley, a 3 kew Zealand. in north Canterbury, New Zealand.

\section{กิ}

$0.01 \frac{1}{2000} \quad 2001 \quad 2002 \quad 2003 \quad 2004 \quad 2005 \quad 2006 \quad 2007$

he can be used to graug satchcan be used to extrapolate from ungar (i.e., homogeneous) ments in hydrologically sin performance in making

regions are developed, and their pefeviewed.

5.2.1 Processes Figure 5.2 illustrates runoff variability scales, from less than New Zeal and across anual variation. Runoff variability hourly up to (red line) is an aggregate measure that is the ann compared to the high-frequency variation, but can damped con to extent by the prence of evente be affecte lotuations. Potentially, the inter-annual fluctuseasonal finff could be disaggregated into a component ations in that direcly and potent a precipitation, especially in relation to potenthe riming of (Montanari et al., 2006), and is sensitive to tial evaporation (Mon variations in rainfall-runoff processes higher-frequency and Sivapalan, 2009). The term (Jothityangkon is used throughout this book to describe evaporation (E) is free water surfaces, soils and plant surevaporation fro is faces, as well as than could be the carry-over of soil moispotential contributionater) storage between years. Fo ture (and groun (2012) showed that this carry-over example, Xu er al. (20noff for catchments dominated by could affect annual in Australia. The factors that contribute woody vegetation in Aunifestation at the annual scale are to these and their
discussed next.

discussed next. A catchment partitions the sequaration, surface storage cipitation events into raciers etc) and subsurface storage (lakes, snowpack, glaciers etc). This partitioning can be (soil moisture, groundwat a water balance equation. expressed formally thing an be examined from the event (storm and inter-storm) scale up to the seasonal (wet and (n) distinct phases can be seen in a dry season) sesponse to individual precipitation and calchith the wetting phase, melting events. one associesses, and another with the dominated by when pration becomes a dominant prodrying phase, when evaporta deep percolation of surface cess. Some processes, suce drainage, operate continuously storages and subsu

during both phases. The catchment's depends upon precipi nd antecedent wetness, the accumucatchment properies, and revious storms. The catchment's lated net effect of mang provends on (i) the water response during the determined by release characteristics of long time scales and by soils topography, geology at long enaporation of water between short time scales, and (it) the evends on the nature, exter precipitation events, which depend of and physiological dyna seasonal and ment. The history of these inis the water balance, but is annual periods is embedd in also ultimately reflected in the type (e.g., petation dynamic behaviour (e.g., phe and the landscape shape. cover, the soil characteristics anfors to millennia which co-evolve on time scales The next sections describe the polimate forcing, cach annual runoff variability, including climate fological) proment (physical) processes, catchment (biological) pr

Climate forcing

and annual runoff variability an Annual water balance an the relative availability of wale governed, to fist or energy (evaporation potential). whe (precipitation) ahiological processes modulate these effects subsurface an the biggest driver of an an This suggests that climate is the bigailability of water an variability. Differences in the and annual runoff variab cesses and global change.

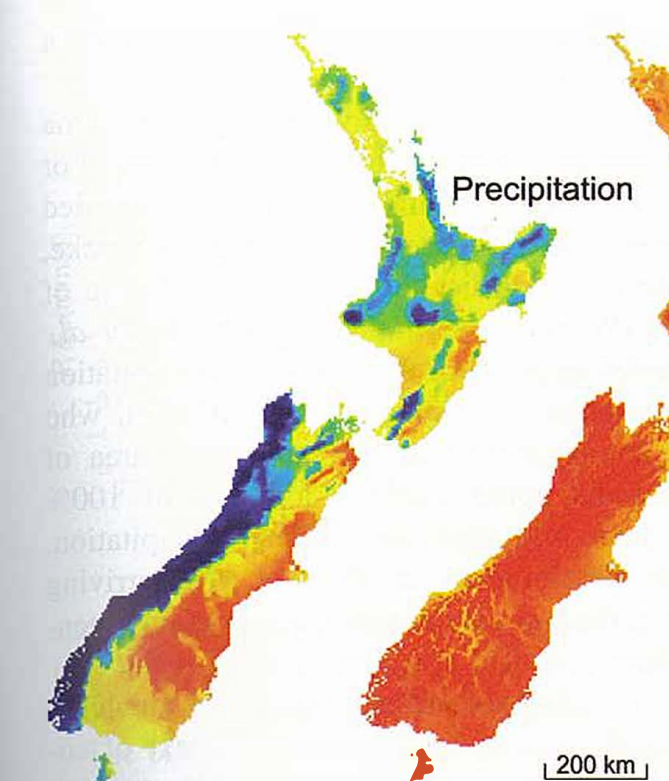

$200 \mathrm{~km}$

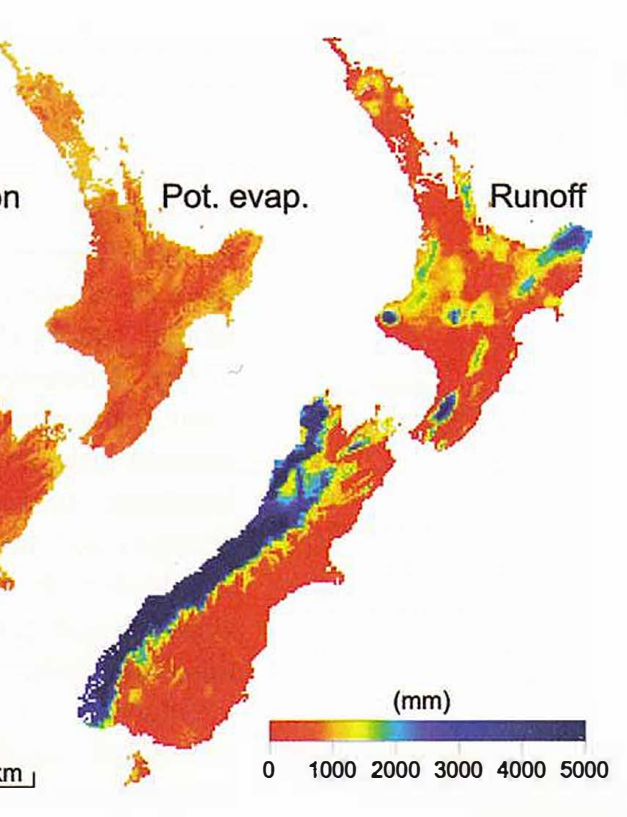

observed in nature, as in the case of the catchments shown in Figure 5.1. The climate in West Virginia is humid, which means that on an annual time scale more water arrives in the catchment than energy can remove it through evaporation. Therefore the magnitude of annual runoff in the West Virginian Williams River is always high. In contrast, Southern California has an arid climate. More energy is available to evaporate water than precipitation provides to the catchment. Hence evaporation is high and mean annual runoff in the Santa Ysabel Creek is low. More interestingly, the aridity of the climate also determines the high between-year runoff variability because of the nonlinearity of the rainfall-runoff relationship. This is due to threshold effects (e.g., the fact that, depending on the year; precipitation can be higher or lower than the potential evaporation) that bean that small differences in precipitation can translate into much higher differences in runoff even at the annual scale. In the Santa Ysabel Creek, such as for the Williams River, precipitation always exceeds potential exaporion at he the rainfall-runoff relationship is more linear, and ben-year variability of runoff is moderate (reflecting between-year variability of precipitation)

Differences in annual runoff variability between catchments, to first order, are caused by differences in the relative availability of water and energy. However, additional factors cresterences in seasonality and storminess of precipitation (2009) is demonstrated by Jothityangkoon and Sivapalan Figure 5.3 presents a futher illustration of catchments. water (mean annul precipintion) and avin avallable epressed through mean in New Zealand, presented on a rectangular grid nationally, governs spatial variations of mean annual runoff, dividing New Zealand into relatively wet and dry regions.

The relative availability of water and energy can be formalised in the form of the aridity index, denoted by $E_{\mathrm{p}} / P$, and defined as the ratio of mean annual potential evaporation to mean annual precipitation. The aridity index forms the basis of several empirical relationships between mean annual evaporation (and hence mean annual runoff) (Budyko, 1974; Turc, 1954). The most famous and widely used one is that by Budyko (1974), which is therefore called the Budyko curve (Fu, 1981; Choudhury, 1999; called the Budyko curve (Fu, 1981; Choudhury, 1999; of mean al, 2001, Yang et al., 2008). It plots E/P (ratio tation) as a function of $E_{\mathrm{p}} / P$ (see Figure 5.4 for over 331 catchments in Australia; Donohue et al., 2007). The Budyko curve is an empirical relationship, and yet it bring out a number of principles that are crucial to the organisation of this book. First of all, it introduces a key similarity index, $E / P$, unique to hydrology, to express the relative availability of water and energy, and thus helps to clative hydrolog Second, while clearly recognising a certain amount scatter, whe fact the most catchments of the wold (on scater, the fach that most calchments of the world (on encer wist-order cont on catch factors elves goved by climate. The relative effects of most

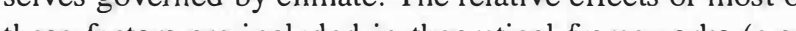
Milly, 1994a, b; Woods, 2003). Or, 1994a, b: Wods, 2003).

oes contribute to annual runoff variability is the relative seasonality of annual precipitation 


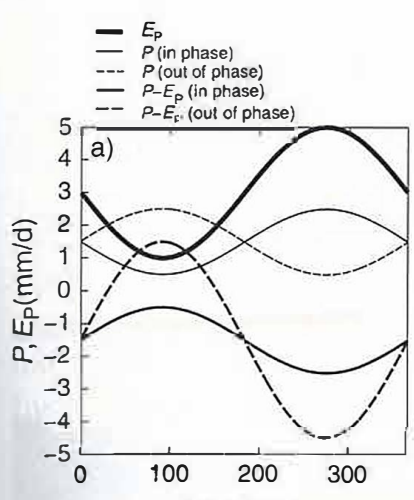

Day of year

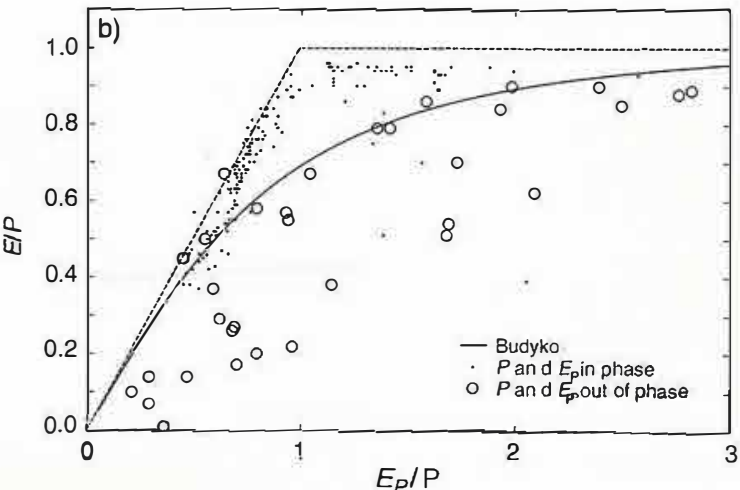

Figure 5.4. Budyko curve and points representing 331 catchmen Australia. Large, hollow circles denote the 30 moderate-sized catchments $\left(21000 \mathrm{~km}^{2}\right)$ and small circles denote the remaining 301 smaller catchments $<1000 \mathrm{~km}$. . .

and annual potential evaporation (used as a surrogate for nd annual pote see Milly et al., 1994a, b and Potter et al., energy avallable, potential evaporation $\left(E_{\mathrm{p}}\right)$ coincide with annual maxima in poteniatation $(P)$ - or out of phase - where annual maxim in $E$ coincide with annual minima in $P$ (Figure $5.5 a$ ). Many regions of the world exhibit strong seasonality in climate forcing, ranging from completely in phase to conpletely out of phase. The relative seasonality of precipitation and potential evaporation has significant impacts on ton and inter-annual variability. In catchments where rainfall and potential evaporation are out of hase, runoff production is enhanced, and evaporation phase, lines in Figure 5.5a), there is an excess of water compared thes in furing the wet season. When this water accumuthe ability of the catchment to store it, runoff lates beyond the a contrast, when $P$ and $E_{\mathrm{p}}$ are in phase is gener lines in Figure 5.5a) or there is no seasonality at (dashed lines ion reduces the accumulation of water, and , This phenomenon explains thus reduces runserved in otherwise arid regions: although why run south-west of Western Australia and Southern California have a deficit Western Austion compared to energy, during cool we of precipitato is a localised water excess that generates winters the is a lin other arid places seasonal phasing runoff. Note the domina less inporter in the catchment runoff mechanism af effects of in-phase and out-of matters less). Th are highlighted in Figure 5.5b, which phase seasonality ater balance data from the USA withi presents ante framework, with the catchments stratified a Budyko style frapitaion and $E_{\mathrm{p}}$ are in phase or out by whether precipvations show that evaporation is reduced

ff enhanced) in catchments where precipitation nd $E_{\mathrm{p}}$ are out of phase

Of course, within-year climatic variability on all time scales can impact annual runoff variability. For example, the statistics of rainfall inter-aegetation uptake, by runoff gen to predict the mean and variance of have been shown (Porporato et al., 2004; Zanardo et al., 2012). A detailed example of the effects of precipitation timing was presented by Monf in the monsoonal area of Northern Australia could vary by a factor of $100 \%$ between two years with equivalent annual prear arriving solely due to precipitation in the wet yeation potenslightly later in

An wathingear climate variability Analyses of the effects of within-year clis context of coon annual runoff have to be put in the context of co evolution of climate, soils and vegetation, because over time the landscape and vegetation adapt to the to a parforcing and develop functional featu a compartive study ticular region. This was illustrated by (2009) in Australia by Jothityangkoon and Sivapalan (2009) in which showed that the dominant climate regimes (e.s seasonality dominated in Western Austalia, stormines ability of annual runoff.

Catchment (physical) processes

sepresenting the first-order

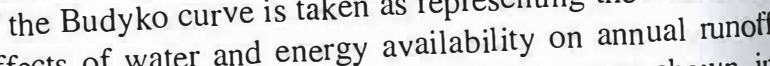
variability, then the scatter around the curves shown in Figures 5.4 and 5.5 is evidence of the second-order effects of catchment storage on annual runoff. Based on detailed analysis of hundreds of catchments across the continental USA, Wolock and McCabe (1999) concluded that, to improve predictions of mean annual runoff beyond seaBudyko relationship, soil moisture storage capacity, seasonaty in water supply and seasonality in worr had to be accounted for.

Catchment storage includes temporary storage in the Cotchmentor soil moisture and longer-term storage in lakes, glaciers and groundwater. Climate fluctuations tha lead to an excess of water, relative to the capability of the entere infiltrate and store water, will favour 0 atche expense of evaporation. On he ond climate fluctuations that promote the ing he other ration and since they provide the opportunity for wat evaporaton, she storage effect can be pronounced on to be evapime scales where soil water storage can pronseasonal water for evapining vegetation that otherwise woll survive such long droughts. Alternatively, the catchment may store water in locations that do not favour evaporation, such as deep, slow flowing groundwater.

The effects of soil type on average annual runoff have been identified by, for example, Wang et al. (2009), who showed that soil textural differences may strongly modify the impact of climate on regional water balance. Specifically they found evidence in Nebraska, USA, that soil texture (via influences on recharge and groundwater storage) can exert a significant control on mean annual wate balance and inter-annual variability of water balance at balance and inter-annual variability of water balance at catchment scales. In Australia, Potter et al. (2005) concluded that infiltration excess is a likely cause of significant deviations between predicted and actual values of average ann
catchments.

Topographic variation is another catchment characterislic that can change the annula war balance. On sloping sites, the water balance can be viewed as a On sloping between subsurface drainage and veretation uptake, mediated by soil moisture. Conditions that favor, (e. . steep slopes, permeable soils) then lead to higher annual runoff via subsurface flow and lower stoger wheres poor drantily (e.g. flat land, less perme soils) lead to higher storage and less land, less permeable accumulation of water sto surface runoff. matic inputs are strongly seste An excellent ex of soil type (texture) and topographic slope have an the spatial distribution of a precipitation) is the Illinois River (as a ratio of annual (Figure 5.6). In this case, a modelligasin in Oklahoma (2012) showed that case, a modelling study by Li $e t$ al. ablc as one moves from while the topographic slope ast towards the outle direction, giving rise to slope also increases in the same annual runoff provides a good first-onder

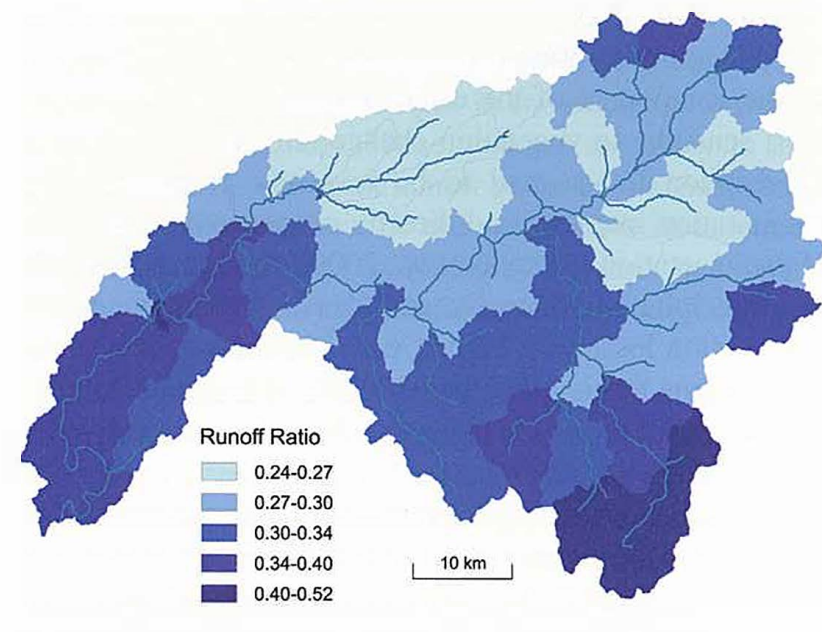

Figure 5.6. Annual runoff ratio (mean annual runoff to mean annua precipitation) estimated for several subcatchments within the From Li et al. (2012).

catchment processes tend to determine the relative contributions of surface and subsurface runoff (Reggiani $e t$ al, 2000: Sivapan et al 2011b). This (Reggini et al. in the Illinois River basin, with saturation excess the domint in catchment whers subsurface flow was he don un off process in the west neer the catchent outer (Li et al., 2012; see also Chapter 10).

Other catchment processes that impact on annual runoff variability include channel transmission losses in arid regions, storage of water by lakes and wetlands, contributions of regional groundwater aquifers, and snow storage and melt processes in cold, humid regions. To provide a detailed representation of these various catchment effects and their impacts on annual runoff, especially in large heterogeneous catchments, one may need models, which are discussed in Chapter 10 

woody vegetation was shown to buffer annual transpiration more effectively than non-woody vegetation, presumably
due to differences in root zone depth (Xu et al., 2012). partitioning of the water balance and a driver of the annual water balance dynamics. Vegetation is also a significant soil (Borgogno et al., 2009; Thompson et al., 2011a). In

Vegetation also displays adaptive features on season and inter-annual time scales. For instance, many pla grow fewer leaves or actively shed leaves during periods of water stress, creating a relationship between leaf area and water availability, and reducing the transpiring surface area. These relationships may allow water balance partitioning to be inferred from observation of metrics of catchment 'greenness' such as the normalised diffindexvegetation index (NDVI). For instance, the Horton index a ratio of evaporation to plant-available water on annual time scales (Troch et al., 2009) - appears to be signin. cantly and negatively related to catchment-scale 2011). NDVI in most water-limited basins (Brooks et al., and to mean annual NDVI across 320 test basins stratUSA (Voepel et al., 2011). Ultimately, vegetation srutegies modulate transpiration to prevent negative extrentilit in plant water potentials, and in doing so reduce varrabmeasin catchment water balance. When water balance is meas ured in terms of the Horton index, for instance. being ured inal variability is markedly damped, primarily bein expressed in terms of the partitioning of water to mealce: runoff generation (Troch et al., 2009), and with the grent runoff generation (Troblance arising in the fast flow con sensivity in wate effectively sequestered from vege mean annual evaporation) and in mean annual precipitation water uptake (Harman et al., $2011 \mathrm{la}$, b). In Australia, Vegetation cover is therefore both a response to the driver of weathering, of soil biogeochemistry, and a determinant of soil hydraulic properties (Thompson et al., 2010 Lucas, 2001). The role of vegetation in modifying its local hydraulic environment can result in striking organisation of the landscape. For instance, modification of soil hydraulic properties by vegetation can result in the formation of spatial patterns in vegetation distribution, in which bands of vegetation are interspersed with regions of bare northern hemisphere rugged landscapes, the difference in energy balance between north- and south-facing slopes regularly leads to drought-adapted vegetation communities on the south-facing slopes, and mesic vegetation on the north-facing slopes. These vegetation differences are also reflected in differences in soil depth, and carbon and nutrient content (lower on the south-facing slopes) (Burnet et al., 2008; Klemmedson and Weinhold, 1992; Franzmeier $e$ t al., 1969). These differences alter the storage capacity and habitat quality of the slopes, providing a positive feedback that exacerbates the differences between slopes with different aspects, and ultimately driving both water balance and catchment evolution (with vegetation, for instance, suppressing erosion and runoff on north-facing slopes, e.g., Cerdà, 1998; Istanbulluoglu et al., 2008).

The consequent increases in aridity in this strongly seasonal Mediterranean climate led to more dramatic reduc tions in river flows to Perth's dams. For example, the $16 \%$ reduction in precipitation led to a 55\% reduction in runoff Predicting runoff response to climatic changes is no usually this straightforward (Montanari et al., 2010). For example, reductions in precipitation could lead to increased water stress on the vegetation, leading to possible forest thinning, changes in vegetation composition disease infestation and die-off, all of which can modify annual runoff. The Budyko curve cannot capture the transient changes in annual runoff associated with these modifications, and may not be sensitive to vegetation or soil changes even once the catchment reaches a new equilibrium.

Increases in average temperature promote not only vegetation change, but also changes in snowfall, snow storage and snowmelt regimes. These changes are likely to alter seasonal runoff, and result in new patterns of annual runoff as well. Several regions of the world have already seen major dramatic changes as a result of increases in temperature, e.g., the Himalayas in India and Nepal, and California in the western USA

Since seasonality of climate, distribution of precipitation throughout the year, and temporal patterns of precipitation can be key determinants of inter-annual runoff variability (Montanari et al., 2006), any changes in the seasonality of these controls can also impact annual runoff. There are historical examples where changes to the monsoon dynamics and timing have led to huge changes in annual runoff variability and collapse of entire civilisations, as in the cases of the Indus Valley (Giosan et al., 2012) and the Maya (Medina-Elizalde and Rohling, 2012).

Effects of global change
Given that the primary control of annual runoff variability is climate, through the relative availability of water and energy, changes in the magnitude or timing of precipitation and temperature (or potential evaporation) could contribute to major changes in annual runoff. A first-order indication of the expected change can be approximated via the Budyko curve Changes in mean temperature (and hence cin he expressed as changes in the aridity index $E_{E} / P$. Depending on the magnitude of this change one could 'move along the Budyko curve' and determine the value of EIP. For example, if the potential evapo remains constant and annul precipitation decreses, $E_{p} P$ will then increase (i.e. become more arid), and $E_{\mathrm{p}} / P$ runoff would be expected to decrese. A dramtic illustraton of exactly this effect arises in soub-west WestaAustralia, as illustrated in Figure 5.8 . Observation recerd a Jarrahdale (near Perth) over 5. Observation record at annual (nrecipitation went throug a $16 \%$ sep-chicate reduction in 1975, and another sill $16 \%$ stem in 1997. changes are the remaining catchment-scale factors altering annual runoff. Examples include forest planting and harvesting, forest conversion to agricultural crops and urban settlements, regulation of runoff by upstream storage an withdrawals for consumptive use (irrigation, municipal and industrial use) (Peel et al., 2010; Vogel, 2011). Vegetatio change can be caused by human intervention, or may occu because of adaptation to climate change. For example. replacing a forest with crops or pasture typically redecs evaporation increasing manifest differently in different environments, dependin on the runoff generation processes. The effect of land use and land cover change on runoff has been the subject many pared catche subject of Peck and Williant Smettem, 2006), neling, for instance, that Bari and Smeten, 2006), revealing, Bor instance, that transient efforestation than deforestion pexperime, the land changes dispopotiontely afect low flows, and that here atmospheric conditions become favourable for dying, vegetation stomatal responses may ing 


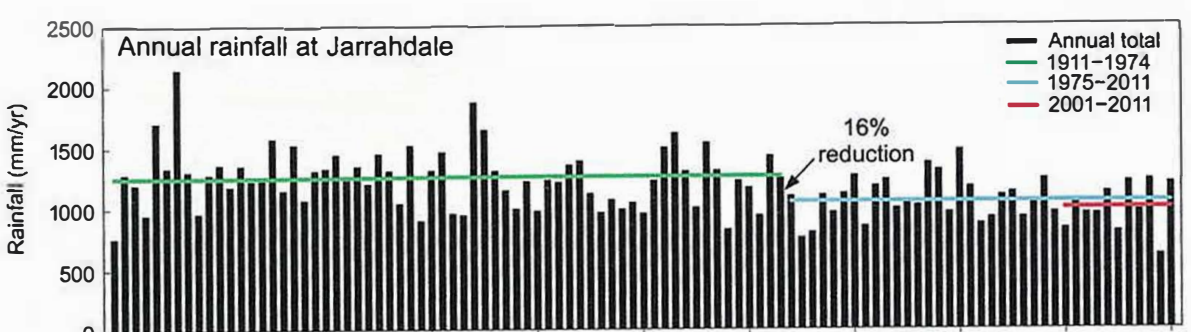

Figure 5.8. Reduction in runoff in and its relation to annual rainfall Data from the WA Water Corporation.

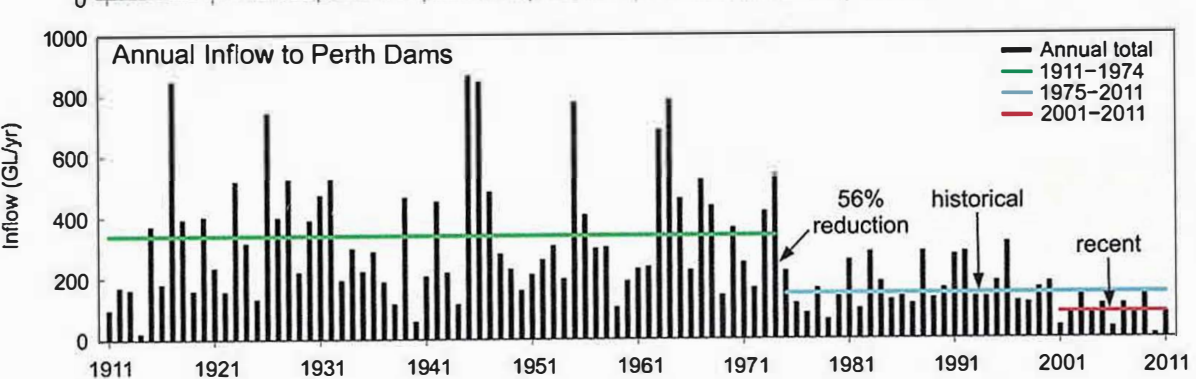

is considerable variability in the timing and sometimes directionality of water balance responses to change (Andréassian, 2004: Brown et al. 2005).

\subsubsection{Similarity measures}

The process controls on annual runoff variability described above point naturally to indices or similarity measures tha can be used to organise regions into groups with similar hydrological characteristics. Similarity measures can be

Runoff similarity: Based on runoff data, the similarity between catchments can be expressed in terms of mean annual runoff (flow volume rescaled by catchment area), or in terms of a runoff ratio (or coefficient): the ratio of mean annual runoff to mean annual precipitation. Inter-annua variability can be expressed in terms of the coefficient of variation (CV) of annual runoff, or in terms of a growh curve (cumulative distribution rescaled by the mean). Catchment responses to dynamic changes in climate land use can be captured in terms of runoff elasticity, i.e. proportional change in runoff divided by proportion change in the climate or land use feature. For example, the precipitation elasticity could be defined as the proportional change in annual runoff over the proportion change in annual precipitation.

Climate similarity indices: Given the primary control of water and energy availability on annual runoff variability, the aridity index, $E_{\mathrm{p}} P$, is an obvious climate similarity measure with a proven predictive capacity. Figure 5.9a shows a glob map of the aridity index. Locations with high aridity index , i.e., mean an mall fraction of mean annul precipitation.
Within-year variability and in particular the relative seasonality of (or phase difference between) precipitation and potential evaporation also impact runoff variability. This seasonality can be computed with a seasonality index. $\left|\delta_{P}-E_{\mathrm{p}} \delta_{E} / P\right|$, where $\delta_{P}$ and $\delta_{E}$ are the amplitudes of the precipitation and potential evaporation curves. Figure $5.9 \mathrm{~b}$ presents the global distribution of the phase differences between precipitation and potential evaporation. A combination of the aridity index and the relative seasonality are needed to predict annal rinofr in some regions. For example, in Mediterranean climates (e.g., south-west Western Australia, Southern California, southern Spain etc.) observed runoff amounts are inconsistent with predictions made from the annual aridity index: the prevailing out-of-phase seasonality (Figure 5.9b) elevales seasonal runoff production. Figure 5.9c shows the inter-annual variability of annual precipitation, expressed as the coefficient of variation; it is typically largest in arid locations (Figure 5.9a)

Catchment similarity indices: Within a region with homogeneous climate (e.g., similar aridity values, similar seasonality of precipitation and potential evaporation). differences in annual runoff relate to catchment processes. e.g., storage and vegetation uptake. Similarity indices 10 describe these processes should reflect soil water holding capacity, soil texture (or saturated hydraulic conductivity. opographic slope and vegetation cover

A dimensionless similarity framework for quantifying the relative roles of multiple factors in annual water ance was developed by Woods (2003) based Yokoo el $a$ (2008) bork by Milly $(1993,1994 a, b)$, and by (2008) based on the physically based moder of an francwater balance by Reggiani et al. (2000. A and Sivapala

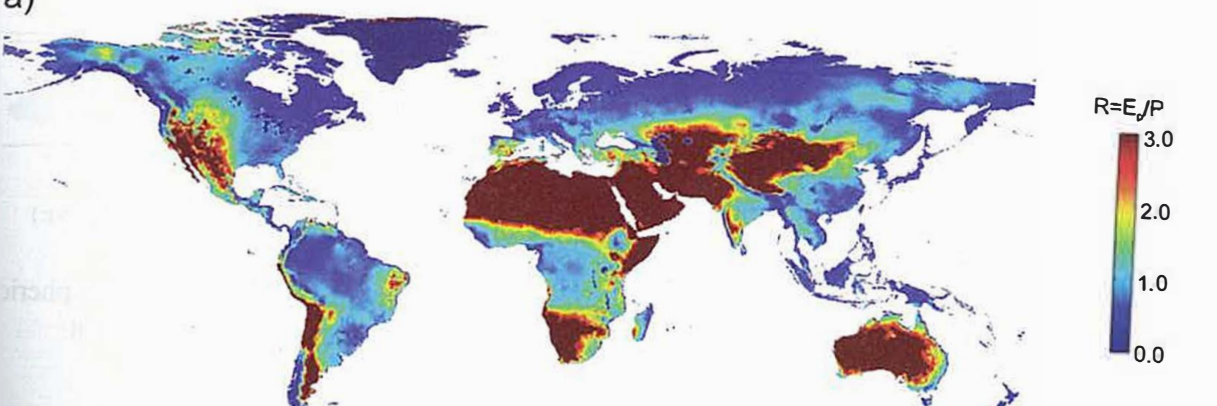

b)

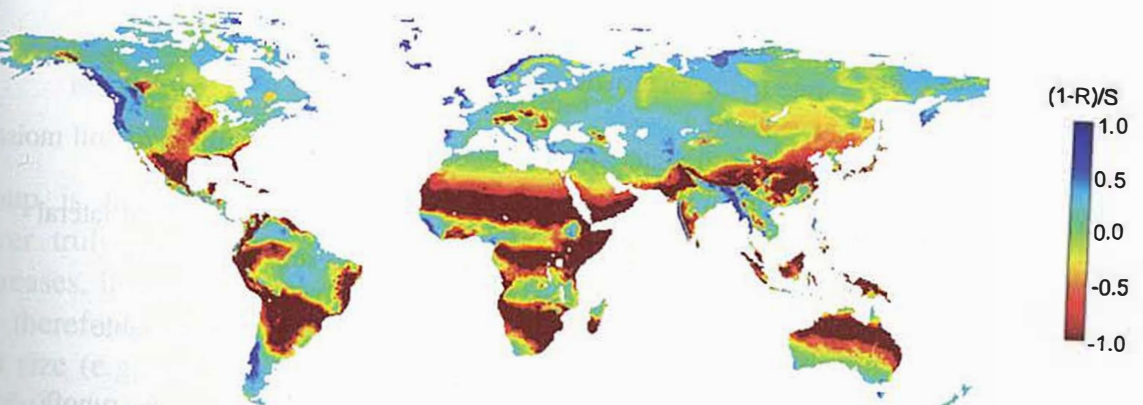

90 annual of vacipiation of the 1961 Mitchell and Jones (2005).

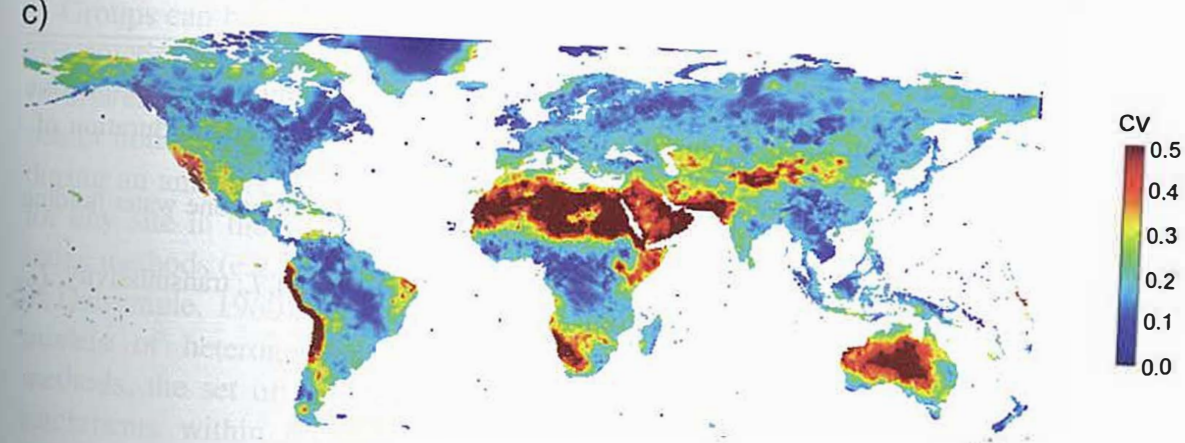

(2009) with similarity indices expressed as a ratio of cliexample of catchent time scales. Table 5.1 presents an example of catchment similarity indices, 5.1 presents an vegetation and precipitation properties and expling soil, eir physical meaning and context, an al. (2007). These indices measure ratios of fluxagener ge volumes or time scales.

5.2 .3 Catchment grouping

of runoff in urouping is at the core of PUB. The prediction observed in ungauged catchments is based pon wion similar dascribing the bes. Similarity metrics provide a way of of annual runoff. Thour of individual catchments in terms to transfer the next section of this chapter discusses set of catchments ke predictions in another. transfer requires approaches to group similar catchments Theser, and then to use this information for prediction. extent (Chapter 5 and applicable to all runoff signatures section of to 10). We have attempted to make this to provide detapter generic and comprehensive in order that the area idered, is homer study, or the group of catchments conhis conts homogeneous (Blöschl, 2011). Homogeneity in of interest (e.g.,. annual re processes leading to a signature tion curve etc.) are not runoff, seasonal runoff, flow duroneity permits the simplifying assumption sites. for a gue relationship between predictors and the signature frequen group of catchments. The literature on flood prediction and - regionalisation or grouping, statistical Regionalialed background to the relevant techniques. 
Dimensionless numbers for pore-water dominated hydrology at long time scales

\begin{tabular}{|c|c|c|c|c|}
\hline $\begin{array}{l}\text { Dimensionless } \\
\text { groups }\end{array}$ & & Dimensionless number & Interpretation & Application \\
\hline \multirow[t]{2}{*}{ Climate } & $E_{\mathrm{p}} / P$ & Aridity index, $R$ & $\begin{array}{l}\text { Ratio of average demand for } \\
\text { moisture to average supply of } \\
\text { moisture }\end{array}$ & $\begin{array}{l}\text { Approximate water balance } \\
\text { (e.g., using Budyko curve) }\end{array}$ \\
\hline & $\left|\delta_{\mathrm{p}}-R \delta_{E}\right|$ & Seasonality index, $S$ & $\begin{array}{l}\text { molsture } \\
\text { Amplitude of the seasonal cycle of } \\
\text { precipitation minus potential } \\
\text { evaporation }\end{array}$ & $\begin{array}{l}\text { Seasonal pattern of atmospheric } \\
\text { moisture surplus/deficit }\end{array}$ \\
\hline \multirow[t]{2}{*}{$\begin{array}{l}\text { Canopy and } \\
\text { soil }\end{array}$} & $\begin{array}{l}w_{\mathrm{cm}} /(P / N) \\
k \tau_{\mathrm{c}} /(P / N)\end{array}$ & $\begin{array}{l}\text { Canopy storage index, } \\
W_{c} \\
\text { Relative infiltration, } K\end{array}$ & $\begin{array}{l}\text { Ratio of canopy storage to } \\
\text { characteristic rainfall event depth } \\
\text { Ratio of characteristic infiltration } \\
\text { rate to characteristic rainfall } \\
\text { event rate }\end{array}$ & $\begin{array}{l}\text { Throughfall } \\
\text { Infiltration excess }\end{array}$ \\
\hline & $w_{\mathrm{rnm}} / P \tau$ & $\begin{array}{l}\text { Rootzone storage index, } \\
W_{r}\end{array}$ & $\begin{array}{l}\text { Ratio of soil water storage capacity } \\
\text { to annual rainfall }\end{array}$ & $\begin{array}{l}\text { Seasonal filling of soil moisture } \\
\text { deficit }\end{array}$ \\
\hline \multirow[t]{3}{*}{ Saturated flow } & $\begin{array}{l}D L / \\
\quad\left(T_{\mathrm{o}} \tan \beta \tau\right)\end{array}$ & $\begin{array}{l}\text { Advection response } \\
\text { index, } t_{\bullet}\end{array}$ & $\begin{array}{l}\text { Ratio of travel time for advective } \\
\text { signal to duration of seasonal } \\
\text { forcing }\end{array}$ & $\begin{array}{l}\text { Responsiveness of lateral } \\
\text { subsurface flow }\end{array}$ \\
\hline & $T_{0} \tan \beta / L P$ & $\begin{array}{l}\text { Relative transmissivity, } \\
T\end{array}$ & $\begin{array}{l}\text { Ratio of maximum lateral outflow to } \\
\text { characteristic water input rate }\end{array}$ & Depth to water table \\
\hline & - & $\begin{array}{l}\text { Slope of topographic } \\
\text { index distribution, } \omega\end{array}$ & Rate at which saturated area expands & Saturation excess runoff \\
\hline
\end{tabular}

Climate variables: mean annual precipitation, $P$; mean annual potential evaporation, $E_{p}$; dimensionless amplitudes of precipitation and potential evaporation, $\delta_{P}, \delta_{E}$; number of rain events per unit time, $N$; duration of annual cycle, rainfall event, $\tau_{\mathrm{c}}$

Canopy and soil variables: average interception storage, $w_{\mathrm{cm}}$; mean saturated hydraulic conductivity at surface, $k$, roozectis capacity, $w_{\mathrm{n} m}$

capacity, $w_{\text {min }}$. slope of topography (or head gradient), $\tan \beta$.

After Woods (2003) and Wagener et al. (2007).

omogeneity tests for the index flood method. Dalrymple (1960) proposed a test, described in several classic text(190) proposed a test, descibess flood homogeneity by books (e.g., Chow, 1964), to assess imum annual flood peak analysing the variability of the maximultiple sites (see also, $\mathrm{CV}$ and/or skewness (CS) across multiple siles (see also, among others, Lettenmaier et al., 1987, Stedinger (2007b) 1995; Hosking and Wallis, 1997 . Viglione et al. (200 Cas compared the power of several homogeneily tests and Castellarin et al. (2008) showed how the of the tests.

among sites can affect the performance of used in a still more In this book, the term homogeneily is un comprehensive way, to mean hat a singe can be used to describe variability across a greph. example, a group of catchments could beconsicted with geneous if a single regression model, paranr the variabidifferent catchment characteristics, can captro ity of a hydrological signature of intere for the group. geostatistical methods are being applied, then the assu for tion that a given spatial correlation strcture is valid win a given study area effectively enforces hat study area (a single model of the correlation structur methods are used, a group of catchments are hydrolog homogeneous (similar) if the same dominant per drive the behaviour of all the catchments (Werived dis bution approach might hold across a homogeneole gici or a given model structure of a rainfall-runot morater it apply to all the catchments under consideration. Cis - for thi will deal with regionalisation of model parame be fixed io approach to be valid the model structure must bdrologital the whole region: that is, the region must be helthough thi homogeneous in terms of model structure. Ality comprehensive idea of hydrological hom is ary ity) is not rigorously statistically def ined, it is ver practice and will appear throughout this book, When grouping catchments, there is a trade the griul hydrological homogeneity and the size of Larger pooling groups improve the reliability of te pent made for a target catchment, to the an describe the spatial variability). Where process-base 2007). For instance, the assumptions of the derivers grou

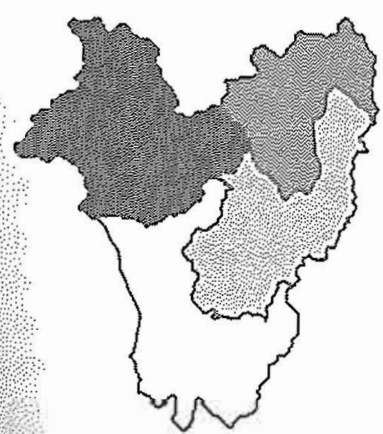

图 region 1

region 2

$\square$ region 3

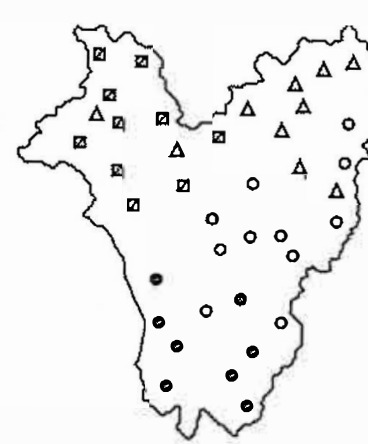

$\Delta$ region 1

- region 2

ar region 4

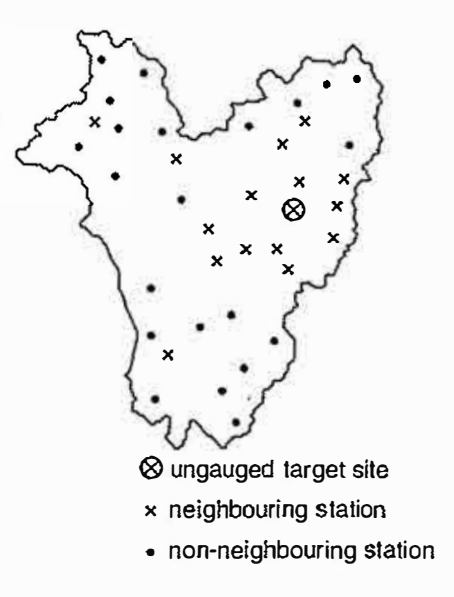

Figure 5.10. Different types of catchment grouping to deternine hydrologically honogeneous regions: (left); non-contiguous regions (middle); pooling group argeted to the site of interest (right). After Ouarda et al. (2001). roup is homogeneous. Pooling groups, however, are never truly homogeneous, and as the size of a group mcreases, it tends to become less homogeneous. Methods are therefore needed to optimise the group compositio and size (e.g., see Reed et al., 1999; Laaha and Blöschl, 2006a).

Groups can be defined in terms of two features: (i) their onstruction (fixed or targeted to the ungauged catchmen f interest), and (ii) spatial contiguity of groups (contiguis or non-contiguous). Fixed groups are constructed once uring an analysis. They are intended to be globally valid or any site in the study area. They are typically used in dex methods (e.g., groups used in the index flood method nodelis of heterogeneous study areas. For regression nethods, the set of individual models for each group of arctiments within the study area is called a regional egression model. Examples of fixed groups are in the first 140 study areas in Figure 5.10. Targeted groups are contricted for each site individually when a prediction is efformed for that site. They are typically used in regiona equency analysis (e $g$ flow index method or region-ofaflience approach, see e.g. Merz and Blöschl, 2005). -ased on the idea of developing different groups for inget site Burn (1990a b) developed the so-cilled regio if influence (ROI) approach, which was further refion inli the addition of a hierarchical feature by Zrinji un 1.994 "ikhi in Figure 5.10.

Both fixed and targeted grouping methods may lead to anngunus (groups) The study ar in sace (regions) or nonubilvided into contiguous regions, while he one 5.10 - in sis subdivided into non-contiguous regions. 1. syed contiguous groups implicity exploit spods *any in addition to other similarity exploit spatial n homogeneous landscapes with smoothly Thathymple, 1960), regression models and geostatistical avitications that are contiguous in mace (regions lead to varying catchment characteristics. A possible advantage of non-contiguous groups is their greater flexibility to include catchments that are scatted in space, but are hydrologically similar

In order to make predictions in ungauged sites, the site of adding further predictive uncertainty to the analysis. For contiguous regions this step is usually straightforward, i.e. graphic location. For non-contiguous groups, an allocatio rule needs to be defined based on available catchmen characteristics for the ungauged site. Statistical method such as discriminant analysis or classification tres (Loo and Blöschl, 2006a) or Andrew's curves (Nathan and on the basis of available catchment characteristics from the data set of gauged catchnents. The criterin are then from the to allocite ungauged catchments to groups.

A number of methods, called pooling methods, are used groups. They differ in terms of how the groups are delin used) and which subjective reasoning or algorthm acteristics, catch ment and runoff che., catchment charaty, etc.) Most of the methos the for a discussion of the stete-of he and of for low flows). ive reasoning is the residual pattern approach. Th apprach assumes that a single model for runoff prediction eity that is not captured in devitions residuals are then mapped and, if pattems in sign and magregions recognised, they are used to delineate contiguous interest needs to be allocated to the homogeneous groups, ungauged catchments are allocated according to their McMahon, 1990) can be used to derive decision criteria for subdividing regions into sub-regions or catchmen

One example of a pooling method that involves subjectdeviations from the predictions, called residuals. These 

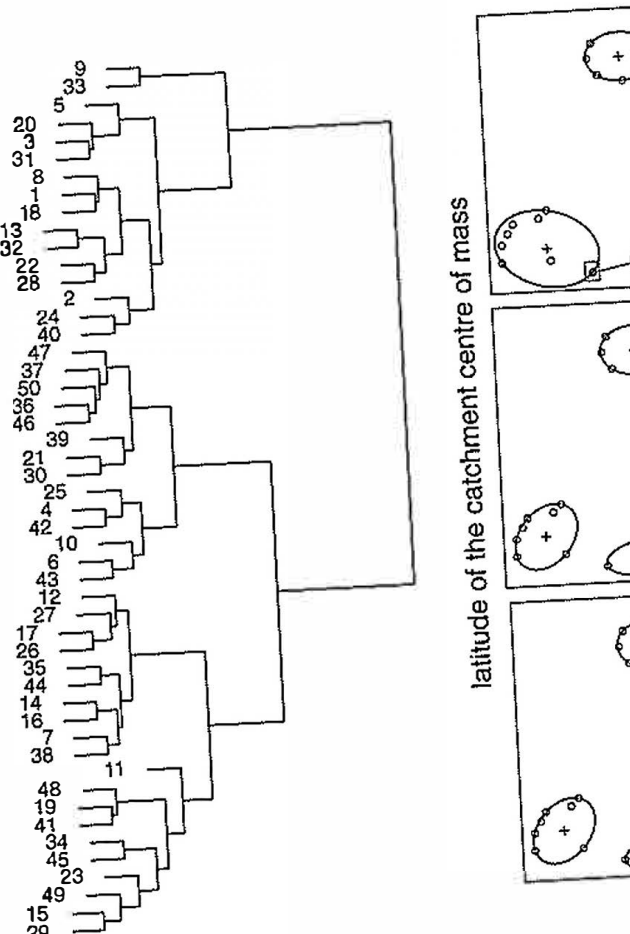

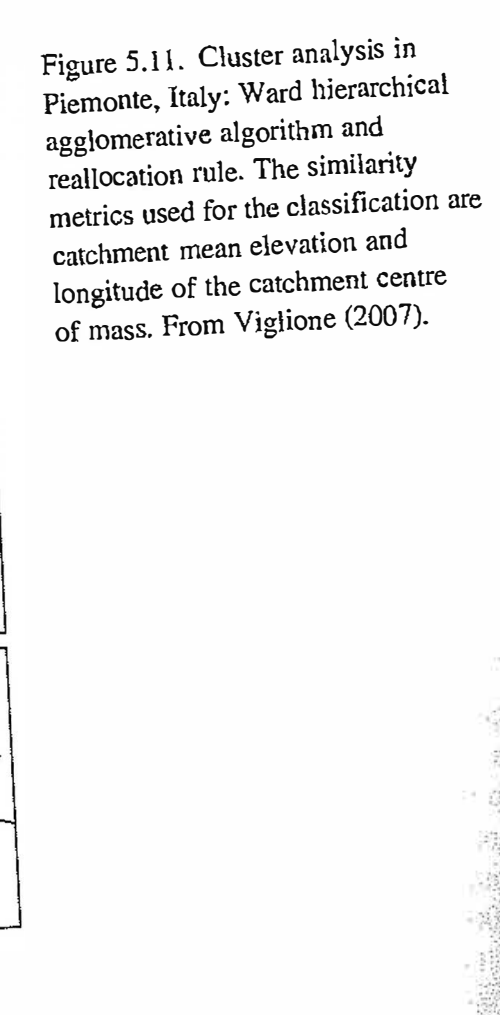

this pattern recognition is done subjectively and the homothis patem rions are delineated manually on maps, choosing their boundaries on the basis of geographic/hydrological interpretation (see Tasker, 1972; Choquette, 1988, Jingyi and Hall, 2004). A drawback of this approach lies in the quality of the initial model, i.e., residuals may be artefacts of an unsuitable model rather than a reflection of localised an unsuitable model rathent characteristics.

catchment characterist in principle, do not need subjective Methods that in example, the cluster analysis methods (see Kaufman and Rousseeuw, 1990; Parajka et al., 2010; Kingston et al., 2011). In cluster analysis, catchmentclimate characteristics are used to automatically classify mate charactinto similar groups by means of a clustering catchinthm. In reality, cluster analysis involves a number of abjective choices (as evaluated by Bower et al., 2004). For example, the selecti on of catchment/climate characteistics to be used and therir relative weighting are crucial (Nas to (Nathan and to set the final number of clusters, which provide a wa the trade-off between hydrological has to acein and the size of the group.

an anse An example of clusue 5.11. The Ward hierarchical algorithm (Ward 1963) is used to classify catchments based on tho (Warderistics: the catchment mean elevation and latitwo char contre of mass. The algorithm starts by assuming tude or contained within its own unique cluster. that each ste is conen progressively merged in a way tha anteed to be optimal. Reallocation procedhe sites. Fo (see Figure 5.16 for example). the basis of seasonal evaporation (Wolock and minimises the information loss (see Figure 5.11, left), where information is measured as the sum of suster deviations of each site from the compl clusters witli The Ward algorithm generates compact clust evenly distributed elements. However, it does is not guarelement reallocation, so the final configuration is not ga be applied concurrently while clusterng the sites tech example, Viglione et al. (2007a) used a reallocation tect nique with the Ward algorithm in a regional a 11 right annual runoff in north-western Italy (Figure 5.11 , to This reallocation guaranteed that every site lay closer to centre of mass of its cluster than to the centres of mass any other group. The final regions are contiguous based catchment characteristics (as shown in Figure right), but are generally non-contiguous geograpin.

The classification applied by Viglione (2007) (Figur 5.11 ) is based on two characteristics: the catchment tile elevation and latitude of its centre of mass. These ver selected because of their correlation with the $\mathrm{CV}$ of ann runoff (see Section 5.3.2) estimated through a statisul method. One alternative to statistical methods for the sel: tion of catchment/climate characteristics for groupling

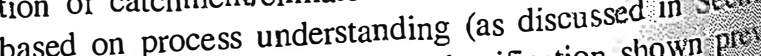
5.2.1 for annual runoff). The classification shown pro ously in Figure 5.5b, for example, grouped calc preipi the basis of seasonality in the relative phase of preet? 4f. anturit area. An early application of regional modelling
1999). Seasonality has also been used for classification to identify low flows and floods (see e.g., Young et al., 2003; Laaha and Bloschl, 2006b), based on the assumption that differences in the occurrence of low flows or floods within a year are a reflection of differences in hydrological processes and can thus be used to define homogeneous regions. Homogeneous groups can be
delineated manually on a map, or by means of statistical delineated manually
grouping techniques.

5.3 Statistical methods of predicting annual runoff in ungauged basins

To predict runoff signatures in ungauged catchments, transfer mechanisms are needed to link information from other catchments to the catchment of interest. Regional statistical techniques have been a topic of intensive exploration in this area. These techniques treat the prediction of a larget variable as the problem of estimating a random variable, while explaining the maximum amount of the tures are used for many different predicted runoff signaures. In Chapters 5 to 10 these methods are reviewed, under the topics of:

More complex multivariate analyses include additional independent variables, e.g., hydroclimate, area, elevation and land cover. Hawley and McCuen (1982) discuss numerous advantages of multivariate regional regression analysis to estimate mean annual runoff. Water yield estimates from regression methods are objectively reproducible, their bias is minimised by the method, and uncertainty associated with them can be quantified under explicit assumptions. A less evident advantage is that regression methods may capture relationships that are evident in the data, but for which no theoretical explanation is available, for example due to the co-evolution of vegetation, landscape and hydrological response. In regression models, mean annual runoff is related typically to geomorphic and climate characteristics. Examples for the USA include Lull and Sopper (1966) and Johnson (1970) for New England, Thomas and Benson (1970) for regions in the western, central and southern USA, Majtenyi (1972) for areas of South Dakota, Hawley and McCuen (1982) for the western USA, and Vogel et al. (1997) for the north-eastern USA. Vogel et al. (1999) developed regional multivariate models to estimate mean and variances of annual runoff across 18 regions in the USA. The results of Vogel et al. (1999) are discussed further in Section 5.5.1. Figure 5.12 presents one case study in north-western Italy (Viglione et al., 2007a). The mean annual runoff was obtained by a non-linear regression with the mean annual precipitation and the catchment average elevation. Elevation provides a surrogate for temperature (and therefore energy, vegetation type, snow processes and their seasonal variation). Cross-validation results are shown, along with the $90 \%$ prediction intervals for the regression in Figure 5.12b.

Duan et al. (2010) used principal component analysis to relate 51 years of annual runoff data for 11 stream gauging stations in north-west China to annual precipitation, oration and catchment characteristics. The regional regresoration and catchment characteristics. The regional regression model accounted for $87 \%$ of the variance in the runoff
estimates. The eight variables included in the model are annual precipitation, variables included in the model are annual precipitation, annal surfece water evaporation, tion, sub-basin area, sub-basin wetland area and sub-basin shape factor.

53.1 Regression methods

ferm annual runoff

Cressions are one of the simplest statistical methods 4.41 to estimate mean annual runoff. The relationships - exploit independent variables that are prime drivers 4. ninoff generation, for example, mean annual precipita4.17: Or that are clearly related to runoff volume, such as renhical ani is il -

\section{Inter-annual variability}

Kalinin (1971) was probably the first researcher to develop an empirical relationship to estimate the coefficient of variation of annual runoff (CV). The $\mathrm{CV}$ was related to he catchment area through a two-parameter, decreasing, on-linear relationship. The decrease of the CV of annual runoff with area is to be expected, as a result of space-time averaging. McMahon et al. (1992) related the CV to the mean annual runoff with a power-law relationship, which 

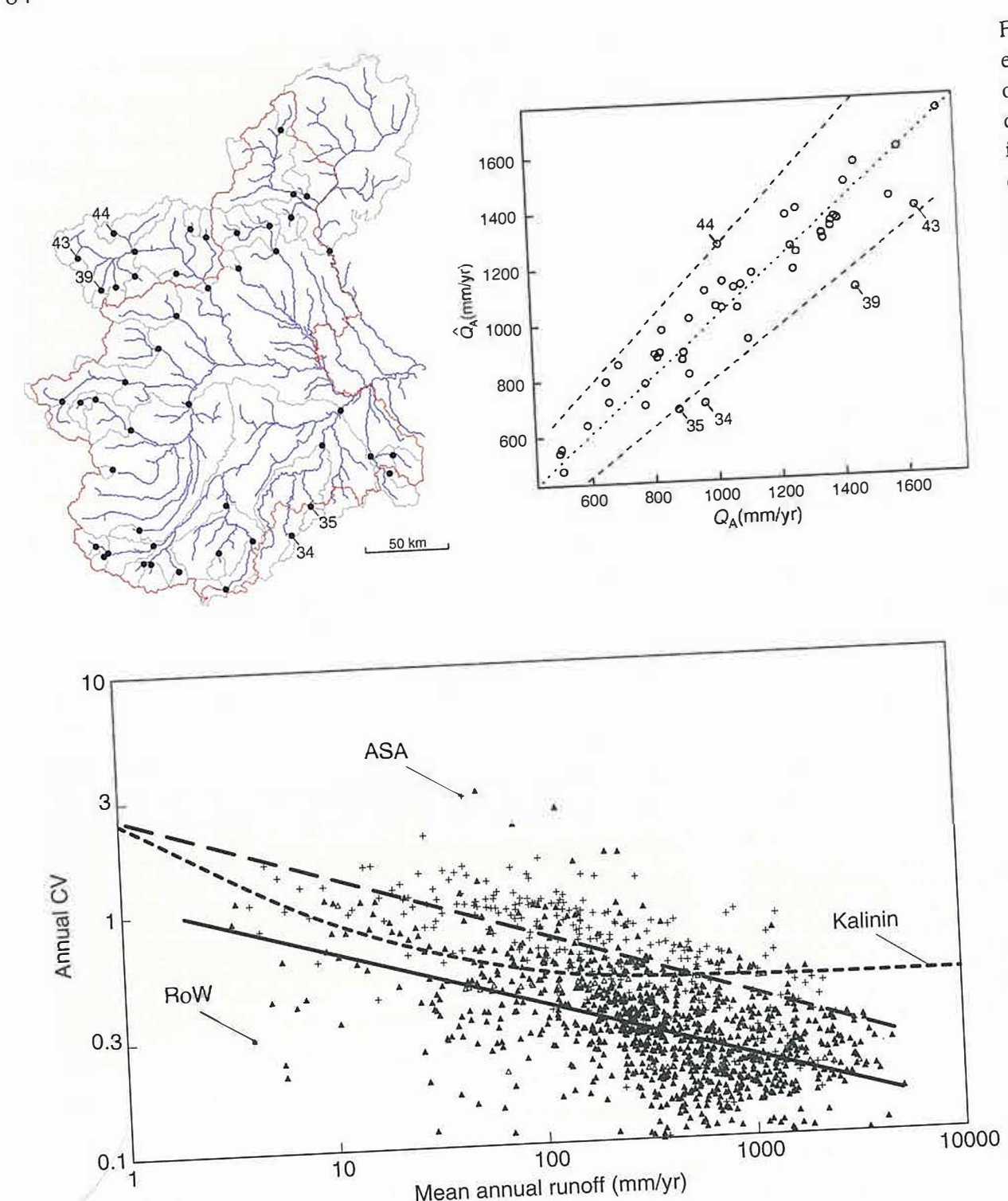

Figure 5.13. Coefficient of variation of annual runoff versus mean Australia and Southern Africa (ASA), solid line relates to the rest of (ASA), solid line relates thahon et $c$ 12007b), Koster and Suarez (1999).

Mean annual runoff (mm/yr)

indicated that arid (less rainy) catchments are characterised by more variability. Figure 5.13 shows the results of applying this approach to a global data set, stratified into Australia and Southern Africa and the Rest of the World (McMahon et al., 2007b). The CV of annual runoff in Australia and Southem Africa is significantly higher the the rest of the world, for a given mean antul runoff.

\subsubsection{Index methods}

Index methods assume that the locally scaled signature Index met, or some functional form of it, is the same fo ofl catchments in the group, which is called homoge neous if it fulfils this assumption. In the following, index neous if for mean and variability of the annual runo are discussed.
Fure 5.12. Mean annual runof

observations. The dashe prediction

intervals. The map shows the outlets

of 47 catchments in nonh-western

(2007a) estimated from regressions vs.
Mean annual runoff

Budyko-type models Budyko-type models offer the potential to estimate mean annual actual evaporation fion the aridity index and precipitation withour callibilon Mean annual runoff is then estimated as the residual of precipitation and evaporation. Budkyo-type m'dekop. include: Schreiber (Schreiber, 1904), Ol'dekop (Ol'dekon 1911), Turc-Pike (Turc, 1954; Pike, 1964; Milly 1981 Dunne, 2002), Budyko (Budyko, 1974), Fu (Fu. I Yang Zhang et al., 2004; Yang et al., 2007); Choudhury- iwo(Choudhury, 1999; Yang et al., 2008), Zhang model arameter model (Zhang et al., 2001), and a linear men by by Potter and Zhang (2009). These models are drivential the aridity index, and they do not use explicit conceple isations of catchment processes. They typically include parameter, treated as fixed and not necessarily rela

Table 5.2. Functional (Budyko-type) relationships $\mathrm{F}(\varphi)$ plotted in Figure 5.14

\begin{tabular}{|c|c|c|}
\hline Model & Model details & References \\
\hline Schreiber & $F(\varphi)=[1-\exp (-\varphi)]$ & Schreiber (1904) \\
\hline Ol'dekop & $F(\varphi)=\varphi \cdot \tanh \left(\varphi^{-1}\right)$ & Ol'dekop (1911) \\
\hline Generalised Turc-Pike & $F(\varphi)=\left[1+\varphi^{-1}\right]^{-1 / 1}$ & Milly and Dunne (2002), \\
\hline Budyko & $\begin{array}{l}\text { For the Turc-Pike model, } v=2 \\
F(\varphi)=\left\{\left(\mid-\exp (-\varphi) \tanh \left(\varphi^{-1}\right)\right\}^{0.5}\right.\end{array}$ & $\begin{array}{l}\text { Turc (1954), Pike (1964) } \\
\text { Budvko (1974) }\end{array}$ \\
\hline Fu-Zhang & $F(\varphi)=1+\varphi-\left[1+(\varphi)^{y}\right]^{-1-1}$ & $\begin{array}{l}\text { Fu (1981), } \\
\text { Zhang et al. (2004) }\end{array}$ \\
\hline ameter model & $F(\varphi)=(1+w \cdot \varphi)\left(1+w \cdot \varphi+\varphi^{-1}\right)^{-1}$ & Zhang et al. (2001) \\
\hline Linear model & $F(\varphi)=b \cdot \varphi$ & Potter and Zhang (2009) \\
\hline
\end{tabular}

$\varphi$ is the aridity index, $w, v, \gamma$, and $b$ are parameters

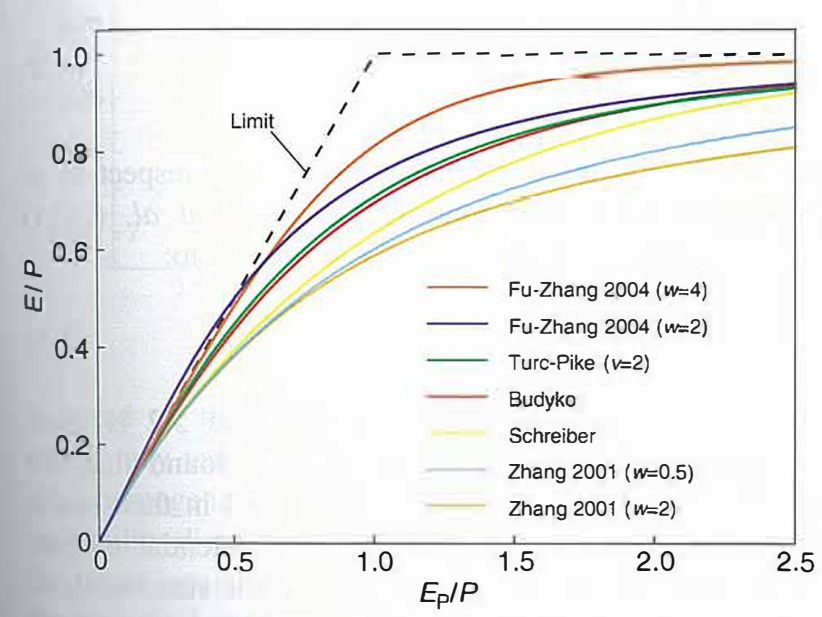

Figure 5.14. $F(\varphi)$ for a collection of Budyko-type methods listed in
Table 5.2.

catchment or climate characteristics. Although the functional forms and parameter values in Budyko-type models are (usually) selected empirically, they do capture hydrological reasoning in the form of the physical constraints of water - and energy - limitation on evaporation. They are classified here as an index-type statistical model, with more hydrological reasoning than a simple regression model, but less than a truly process-based model. 'mproved-Budyko' models, which include addition representations of seasonal or event-scale variability and catchment characteristics to improve model perform an ascussed with other process-based methods in Section 5.4 .

The general form of the Budyko relationship is $E_{A} / P_{\mathrm{A}}=F(\varphi)$, where $E_{\mathrm{A}}$ is the mean annual actual catchchilation and $\varphi$ is the aridity index defined as $E_{A} / P_{A}$ evaporation. Budyko-type models can be treated as an index method because the functional form $F(\varphi)$ can be treated as the climatic homogeneity signature, and the aridity index $\varphi$ as the locally varying scaling index. Table 5.2 presents a list of Budyko-type functional relationships found in the literature. They reproduce the control of annual climate on runoff to differing extents. Their limitations include the omission of seasonal and event-scale variability, and their very limited capacity to represent catchment characteristics.

More recent applications of the models in Table 5.2 relate to estimating mean annual actual catchment evaporation (Zhang et al., 2004; Yang et al., 2008; Potter and Zhang, 2009). With assumptions of a long-term steadystate storage and neglecting groundwater recharge, however, $E_{\mathrm{A}}=P_{\mathrm{A}}-Q_{\mathrm{A}}$, where $Q_{\mathrm{A}}$ is the mean annual runoff. In Figure 5.15 Yang et al. (2007) plotted the Fu-Zhang curves with the fitted parameters for each region (the Tibetan Plateau, Loess Plateau, Haihe River basin and inland river basins) against data from 108 catch ments. In their work, they use the Fu-Zhang equation for predicting the annual water balance in ungauged basins. The annual water balance of a catchment can be represented as (McMahon et al., 2011):

$$
Q_{\mathrm{A}}=P_{\mathrm{A}}\left(1-F(\varphi)-\frac{\operatorname{cov}\left(P_{t}, F(\varphi)_{t}\right)}{P_{\mathrm{A}}}\right)
$$

where $F(\varphi)$, is the annual value of the functional relationship between annual actual evaporation and annual precipitation for year $t$, and $\operatorname{cov}\left(P_{t}, F(\varphi)_{t}\right)$ is the temporal covariance of precipitation $P_{t}$ and $F(\varphi)_{t}$, both considered for year $t$. McMahon et al. (2011) found that the simple Schreiber (1904) relationship performed satisfactorily on 699 worldwide catchments when used in Equation (5.1) 
Catchments in the inland river basins $\Delta$ Catchment in the Tibetan Plateau
Catchments in the Loess Plateau and the plain
$\times$ Cats

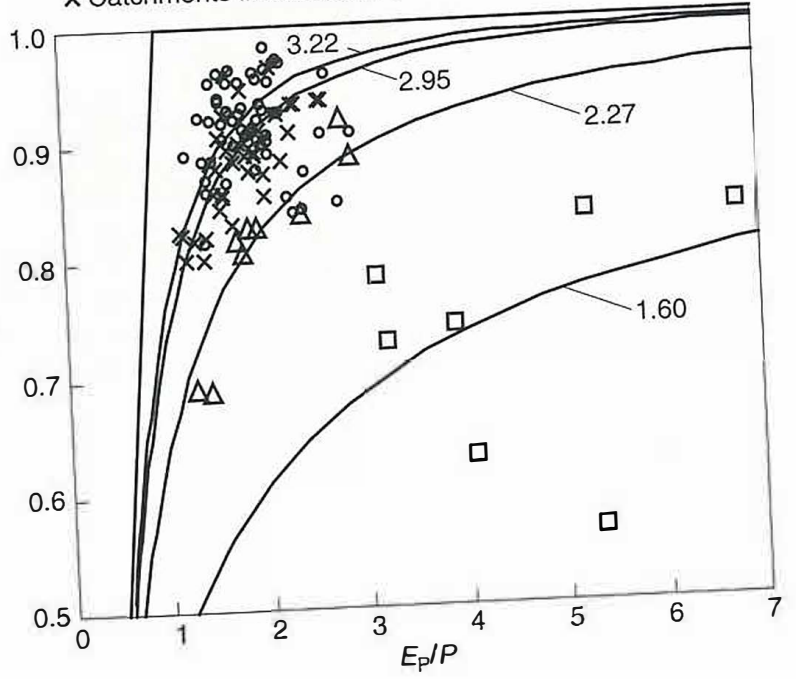

15re 5.15. Fu-Zhang-type Budyko curves, with parameter $\gamma$ fit to data for each region (ranging from 1.60 to 3.22), $Y$ ang et al. (2007). iance term in Equation (5.1) to zero has minimal impact on the mean annual runoff estimates. With this simplification tion holds:

Thus, to estimate the mean annual runoff for a (as either forested or grassland), the Fu-Zhang model can (as either and combined with Equation (5.1). Assuming be applie an are no correlation between annual precitaagain that there is no conoration, this gives the simple relationship:

$$
Q_{\mathrm{A}}=P_{\mathrm{A}}\left(\left(1+\varphi^{\gamma}\right)^{\gamma^{-1}}-\varphi\right)
$$

where $\gamma$ is 2.84 for forested catchments and 2.55 for Zhang et al., 2004).

In New Zealand, Woods et al. (2006) found that the Fuclimatically diverse set of locations. On this basis a chational model of mean annual runoff was
Also, McMahon et al. (2011) show that setting the covarthe mean an simple equation suitable for a PUB applic

$$
Q_{\mathrm{A}}=P_{\mathrm{A}} \exp (-\varphi)
$$
atchment, estimates of mean annual precipitation and catention are required. If the mean ation typology of the target catchment can be defined Zhang model with $\gamma=4.35$ provided a useful approxim tion to long-term point estimates of soil water balance at alidated. In a number of studies, several relationships ander long-term total mean annual air mean annual precipitaided maps were derived using the emperatures from gridavcová et al., 2006; Parajka and Szolgay, 1998).

\section{Inter-annual variability}

dyko-type models Comparatively little research has the inter-annual variability of runoff, relative to

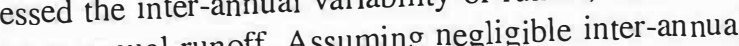
e mean annal runoff. Assuration and negligible covarlance between precipitation a de following relationKoster and Starez (19) derived deration of annual ship for the ratio between the stion of annual precipitation:

$$
\frac{\sigma_{Q}}{\sigma_{P}}=1-F(\varphi)+\mathrm{F}^{\prime}(\varphi)
$$

where $F^{\prime}(\varphi)$ is the derivative of $F(\varphi)$ with respect to $\varphi$ Using the same assumptions, McMahon et al.

$$
\sigma_{Q}=(1+\varphi) \exp (-\varphi) \sigma_{\mathrm{P}}
$$

f the Schreiber (1904) formula in Table 5.2 is used. However, McMahon et al. (2011) also found that, for the 699 worldwide catchments considered in their study, the assumption that precipitation and potential ard deviation were uncorrelated underestim ation of the annual runoff by $\sim 21 \%$. Using an analysis of annual data for 42 catchments worldide, Meen the Dunne (2002) explored the relationship between ty anomaly of annual runoff volumes and the anom runoff precipitation (depth), and the previous year that for volume. Milly and Dunne (2002) concluded that for off was explained by annual precipitation. For arid crange ments the explained variance fell to about $60 \%$ suarez $40 \%-80 \%)$. Starting from the work of Koster and Suased (1999), Sankarasubramanian and Vogel (2002) propond a relationship that depends on both aridity index $\varphi$ and soil moisture storage index (details are in Section s.4. since a derived distribution method is used). All methods neglected the within-year variability of precipiti tion, evaporation and storage, which have been shown affect the inter-annual variability in $Q_{\mathrm{A}}$ (Milly 1994b. see Section 5.4.1)

rebability distribution of annual runoff Regional in quency analysis is a broadly extended statistical procediur to transfer information from gauged to ungauged $b$ arability in potential evapor and potential evaporation, humid catchments $80-90 \%$ of the variance in annual catch-
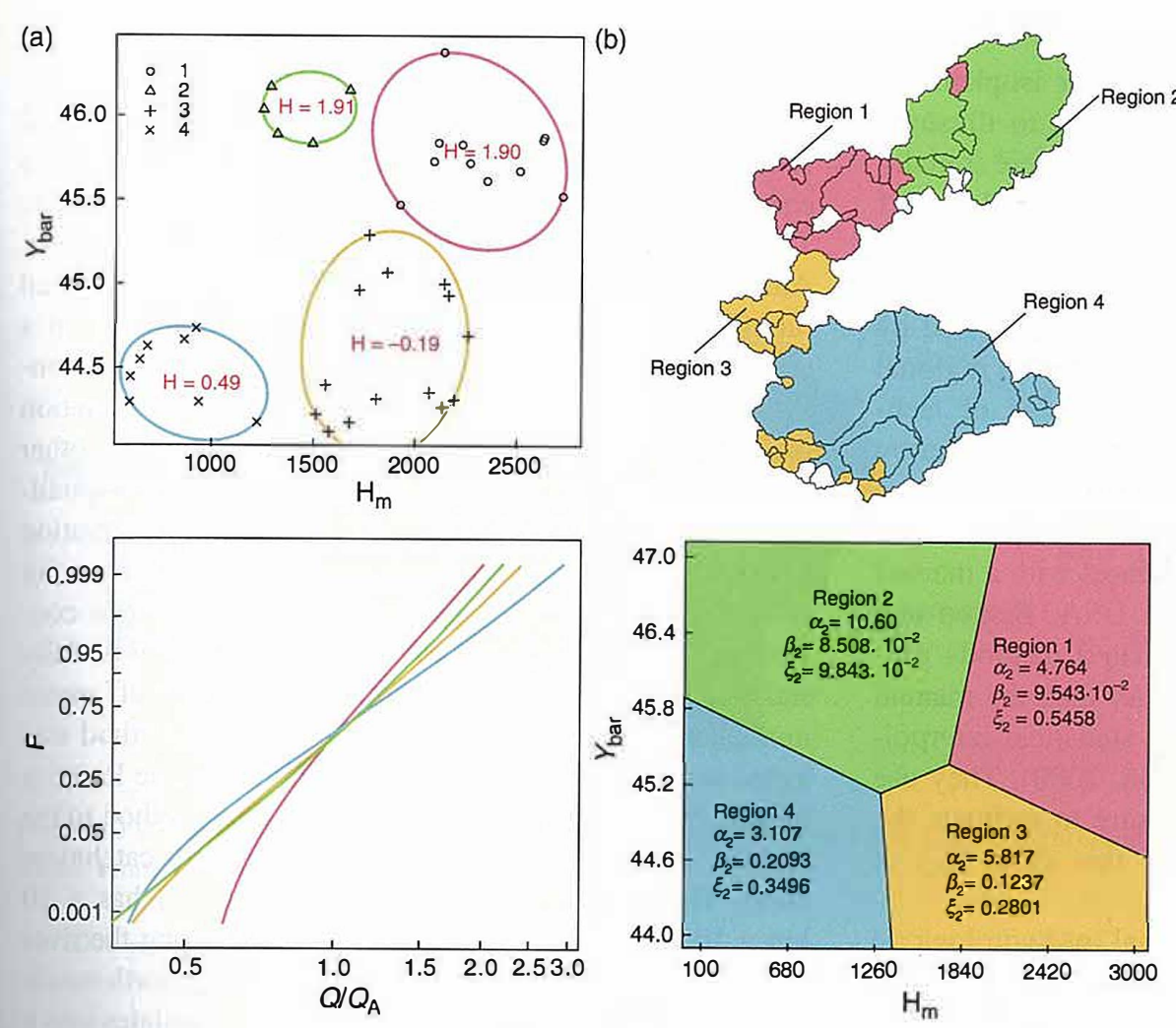

is based on the hypothesis that while the mean annual runoff may vary between different sites within a statistically homogeneous distribution, the remainder of the probability distribution is identical. The regionalisation of the mean annual runoff is usually performed with one of the statistical methods addressed in Section 5.3.1, while pooling of data in homogeneous regions is used to estimate the regional growth curves (i.e., probability distribution rescaled by the mean). Vogel and Wilson (1996) present some applications related to the USA, while in Italy some previous works can be traced back to Ferraresi et al. (1988) and Claps and Mancino (2002). A case study of regional frequency analysis is pro-
vided by the study of Viglione (2007a), who performed an index flow regional frequency analysis in northwestern Italy. The mean annual runoff was obtained through regression (see Figure 5.12), and the betweenyear variability of the annual runoff divided by the mean was considered fixed in homogended by the oblained through cluster analysis. Figure 5.16a shows the results of the cluster analysis (Ward algorith and reallocation) in the space of the similarity indices, this case the mean catchment elevation and the of the centre of mass of the catchment. These antiles have the following hydrological interpretation: mean elevation is a surrogate for temperatue at sea-
Figure 5.16. Homogeneous regions and estimated growth curves for (a) Result of clusth-western Italy. $\left(H_{\mathrm{m}}\right.$ : average catchment elevation (m a.s.l.); $Y_{\mathrm{b} \text {.r: }}$ longitude of the centre of mass of the basin (deg)), of Hosking and Wallis (1997); (b) space; (c) Pearson type III growth curves associated to the four regions ( $F$ : non-exceedance probability); and (d) allocation rule for ungauged catchments in the space of catchmen characteristics $(\boldsymbol{\omega}, \beta$ and $\xi$ are the distribution). Adapted from Viglione (2007a). (a) Result of cluster analysis in the where $H$ is the homogeneity measure catchment groups in the geographic

area correlates to the climatic gradient from the drie south to the rainiest part of the region in the north. These two catchment attributes are related to slope and shape of the growth curve (Ganora et al., 2009). The number of clusters was selected using a homogeneity test (Hosking and Wallis, 1997), and the homogeneous regions are shown graphically in Figure 5.16b. Figure $5.16 \mathrm{c}$ shows the estimated growth curves for the four regions. The Pearson type III distribution was used to model the growth curves. Figure 5.16d shows how ungauged catchments in the region were allows how the groups. The parameters of the Pearson type III distribution to be used as growth curves of the ungauged catchment were chosen by selecting the ungauged region based on its mean elevation and latitude. 1 and 4 present the largest difference in the shape of the growth curves and are at the extremes in she atributes space. Region 1, corresponding to the Valle detributes region in the north-west, is charced by very high elevation and a cold-alpine climate. The by very high variability of annual runoff was less pre between-year other parts of the study ar was less pronounced than in Region 4 located in the sou, and in particular than in elevation variability is atributed to higher. This higher runof variobilty is attibuted o higher mean annul evaporcipitation and runoff 


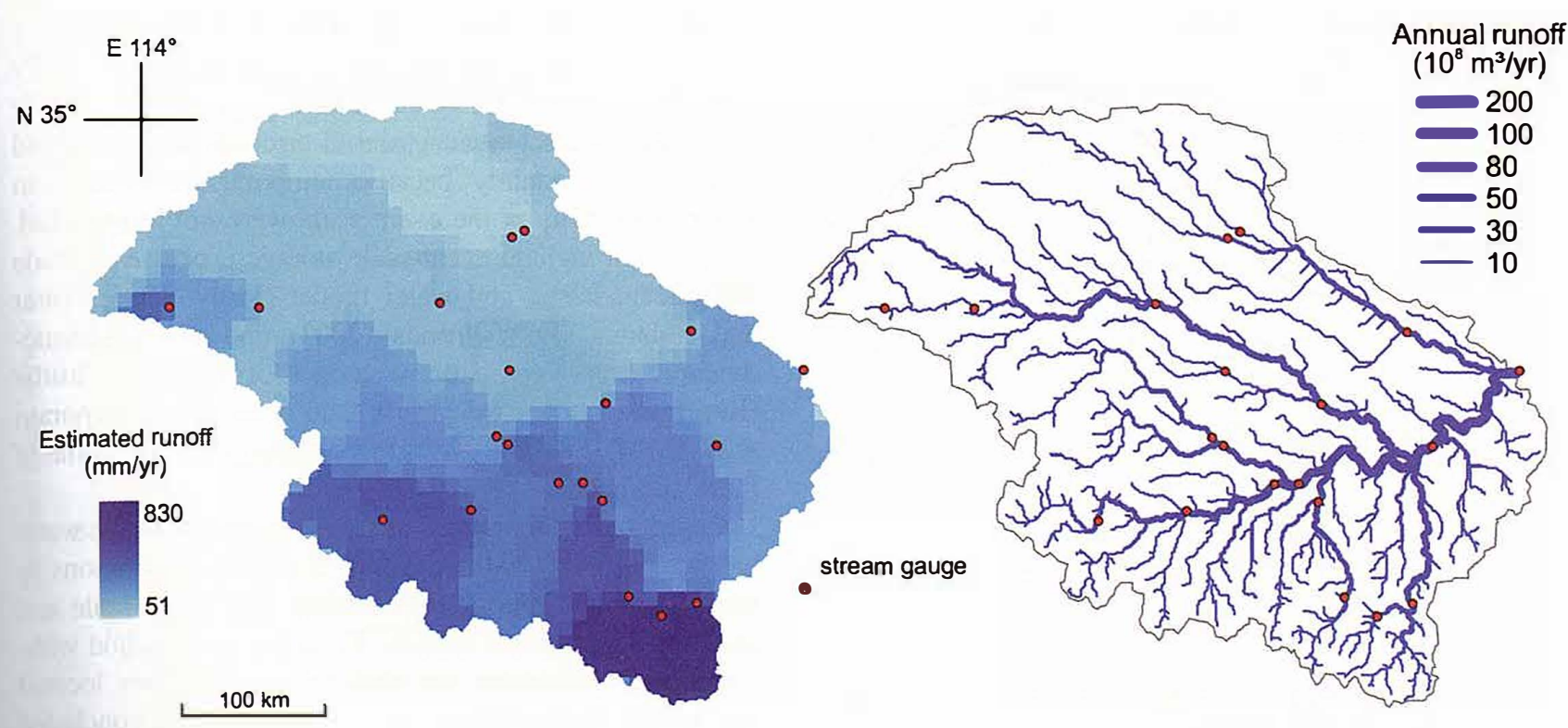

5.3.3 Geostatistics and proximity methods Traditional runoff maps present isolines or isopletlustrate $Q_{\text {A }}$ at the outlet or centroid of a cachms were initially the runoff depth through space. Such drawn from manual interpolation of measurel. 2011). data (Gannett, 1912 referred to by Yan USA were proMean annual runoff depth maps for the (1987) and by duced by Busby (1963) and Gebert er al (1987) region Bishop and Church (1992), who used automad of mapping for the north-eastern USA. A range niques are now available that objectively consider nearby values to determine the isolines and to estim). Based on a across the map (e.g., Hutchinson, 195). Bised on a comparison of eight automated procedures with a manual method to map runoff in the eastern USA, Bishop and Church (1995) concluded that automated methods provided runoff estimates equal to or better than the manual method. These mapping methods are stativo) They use ation procedures (Blöschl and Grayson, 2000). They use spatial proximity as a similarity measure to estimate the value of a variable of interest (in this case $Q_{A}$ ) ungauged locations.

Geostatistical methods also use spatial (or hydrological) proximity as a similarity measure (Merz and Blöschl, 2005), but they are distinct from interpolation methods because (i) they deal with random variables, (ii) they becaunt for the spatial correlation structure and (ii) the accounter redundant information (e.g., when two gauging de clise are close in space and their observations are corstations is this information is considered once and not related in While standard geostatistics applies to problems whe continuous in space (such as meteorological ficlds that are contion in mineral exploration), the problem in or estima is to estimate runoff on a stream network. The hydrology is the topological structure and therefore the difference is distance is formulated. Gottschalk (1993a, b) way spatial disw method for the interpolation of runoff. pioneerd a nact that runoff is to be integrated takes full account on considering the hierarchical structure to strean the distance is of the basin diver network and the covariogram fo measured along he covariogram for the drainage basins, points is replaced model for the whole river syster i.e., a covariogned Building on the work of Gotschalk needs is developed. Bottschalk and Krasovskaia (1998) (1993a, b) and Go beveloped a hierarchical disagSauquet et al. (200(a) soe Sauquet, 2004, 2006). In their gregation method (also basin is divided into sub-basins in a approach, the drainge first level in a larger drainage hierarchy of scales. The well defined by existing observabasin is usually already rivers constituting the first level of tion stations in the mains are in their tum divided into a sub-basins. These bas (or grid cells), and observation stations with appropriate basin scales are chosen as the background for the interpolation. The in equation is satisfied ure guarantees that the water balance equatevel of basins is so that the sum of run equal to that of the first-order to a third level and so on The procedure can be repeas observed Auxiliary runoff values to supplo for points in space in a runoff values can be calculated for empirical relationregular or irregular patcen by min ships and water balance model in toporaphy and other from precipitation stations and on catchment characteristics can be incla runoff observation scale variability not covered by reguretive, the key point networks. From a hydrological persective balance conof the method is that it incorporates wa balance is fully straints, i.e., at confluences the whe with runoff meassatisfied. The method is also consistent with runorh was urements within prescribed uncertainties. The method was tested in a number of regions including the Rhône River th France. Yan et al. $(2011,2012)$ applied $00 \mathrm{~km}^{2}$ cad to Huaihe River basin in China (121000 $\mathrm{km}^{2}$ catch 10 area) The resulting runoff map (Figue 5.17 ) ha a $\mathrm{km} \times 10 \mathrm{~km}$ resolution and the runoff map along the river has a $1 \mathrm{~km}$ basic length unit. There is a strong north-sout

precipitation gradient in the region, which translates in

5.3.4 Estimation from short records ard is available at the por inter-annual variability of the short data series are likely to provide a biased estimate f the runoff statistics. This issue is of particular concern if climate fluctuates on time scales longer than the length of the mensured runoff record. It is unclear, in general, on what time scales climate could be reliably treated as stawhat to speak of long-term mean and variability metnic Regardless, it is still important to account for knistics Regares in is sariability when estim of annual runoff.

Correlation with longer runoff record

A reliability of runoff A conno establish a correlation between a a longer record at a hydrologically shor short iecor ample, Figure 5.18 shows a $\mathrm{mm}$ lar carch with 7 years' data, and a $Q_{A}$ of 1 , who' runoff recor a record of 19 years, whoc $\mathrm{yr}$, along wis $1930 \mathrm{~mm} / \mathrm{yr}$ over the 7 years of commitice mean value $2300 \mathrm{~mm} / \mathrm{yr}$ over the 19 years. The $\mathrm{m} / \mathrm{r}:$ record, and 2300 used to transform the 2300 minns regesien

Figure 5.17. (Left) Estimated mean annual runoff for the Huaihe River basin, China; (right) runoff mapped along the Huaihe River network, China. From Yan et al. (2011).
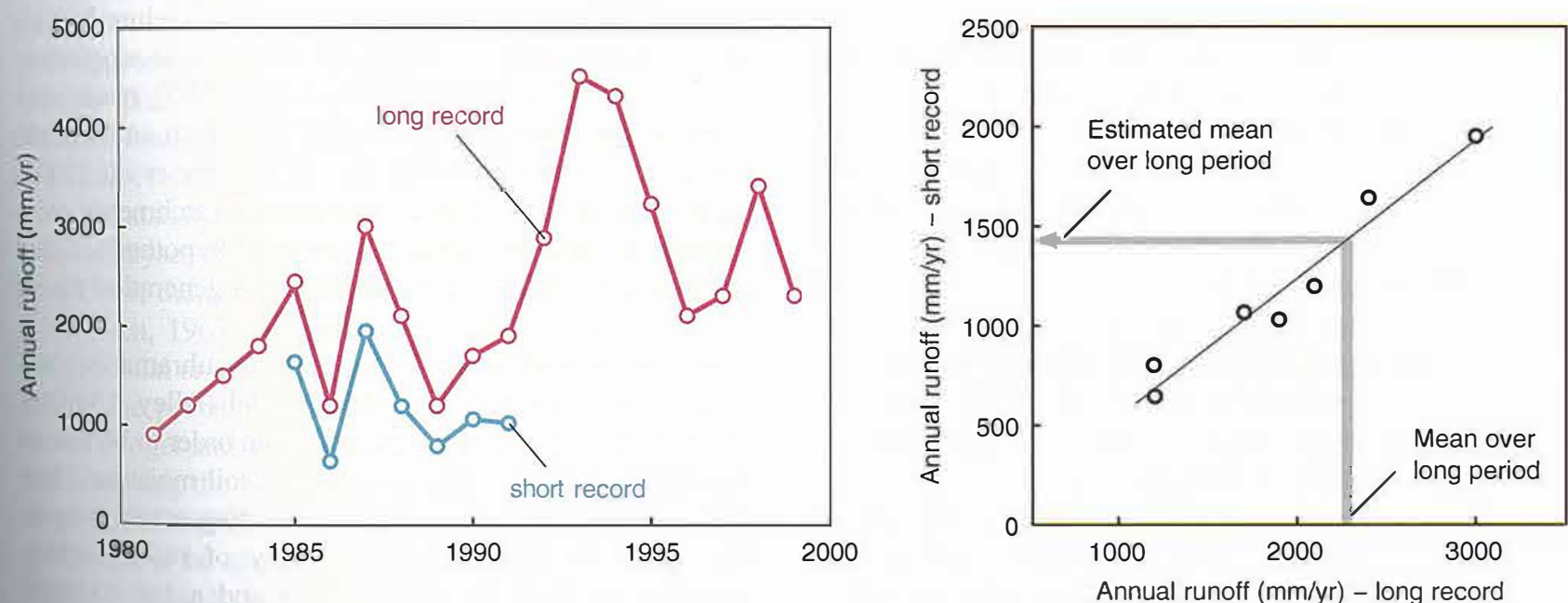

Figure 5. 18. Illustration of using linear regression to estimate the mean runoff when a short runoff record is available, by using a longer record of tydrologically similar catchment.

$1450 \mathrm{~mm} / \mathrm{yr}$, which is significantly different from the original estimate of $1190 \mathrm{~mm} / \mathrm{yr}$

Rainfall-runoff modelling

A second, more complicated method, requiring a long precilation record for the catchment of interest, involves the callibration of a rainfall-runoff model to the shot recies the then runing the model for the full period of the precipition reord. 10 produce a longer runoff ber-annual variability can then be calculd Clealy, this only presented here in the context of the use of short records. More details on process-based methods are presented next in this chapter, and also in Chapter 10.

5.4 Process-based methods of predicting annual runoff in ungauged basins

\subsubsection{Derived distribution methods}

Where an acceptable model of a hydrological process is available, and the probability distribution of the model inputs is known, it is possible to integrate the model 


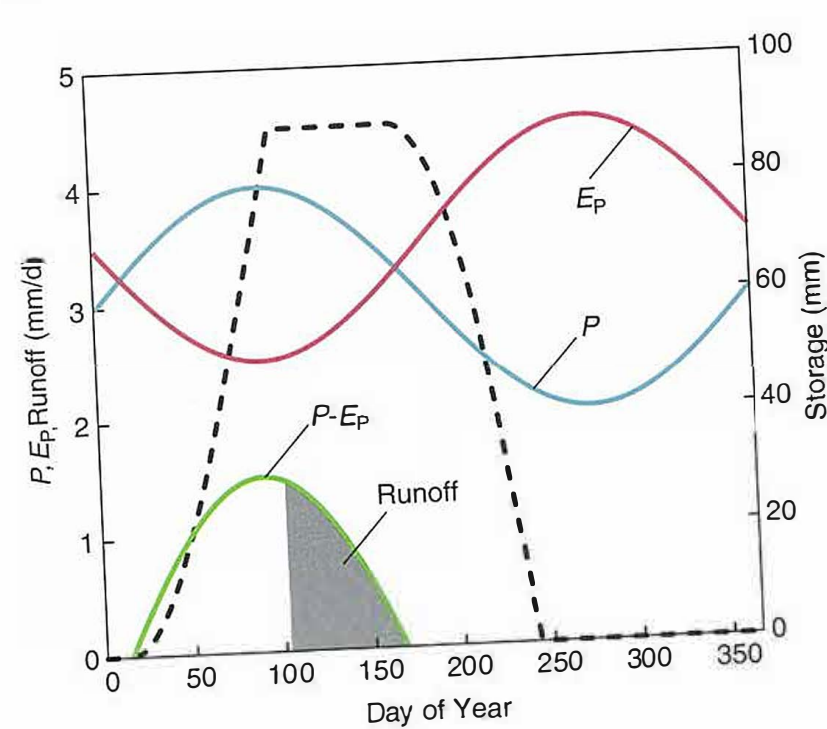

ction between mean climate

seasonality and soil water storage.

equations over the distribution of inputs, to obtain the equations of output. This techprobability distribution of the model on approach. There nique is known as the dervelications of this approach in are many examples of applications Hebson and Wood hydrology (e.g., Eagleson, 1972, Hed Sivapalan et al. 1982; Ramirez and Senarath, 200, time-step) runoff 2005). To estimate annual (or stification to account fo Budyko-type models require the catchment water stoge (Zhote monthly or season et al., 2011). Models that incorporate monthomas, 1981 storage processes include the 'abcd 202), Milly's season Sankarasubramantan and water storage model (Milly, 19940),

seasonal/event model of Wonds (20 example of this type of Figure 5.19 shows a simplified exantion are assumed model. Precipitalion and poten to be sine curves (blue and brown thater available A soi ence (green trace) is the excess wat a ining the first part water store (black dashed trace) of the wet season (when $P>E_{\mathrm{p}}$ ), and once storage reaches its capacity ( $90 \mathrm{~mm}$ in this case), any fur generates runoff (solid black region). The anea to evaporate region is the annual runoff. Water is assumed to evaporate at the potential rate during the wet season and wins (when stored water is present. Once the dy season begins (Wing $P<E_{\mathrm{p}}$ ), storage starts to empty, with water the potential rate until storage is Figure 5.19 can be impleModels such as that shown in Fif climate and soil wate mented for ungauged catchmentable. Global data sets exi holding capacity data are al 2002), poteris for precipitation (New 1994 ) and soil water holding capacily

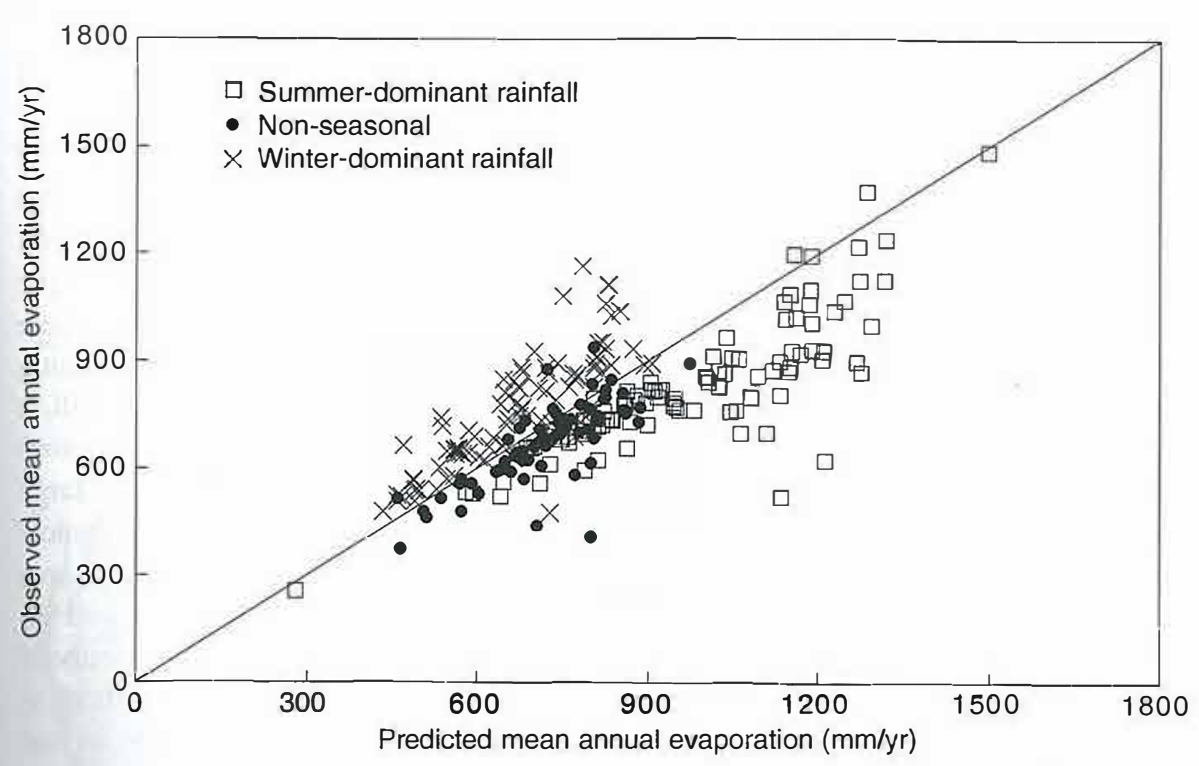

Figure 5.20. Observed mean annual evaporation plotted versus modelle Australia. Catchments are labelled by seasonality of rainfall. The $1: 1$ line plotted for reference. From Potter et al. (2005). 1994b) showed that a model on this shroughout central and to reliably predict ann because temporal fluctuations in water availability at the event scale were not represented. Models that include event-scale storage processes include Milly's stochastic soil water model (Mill and the stochasticand Zhang, 2009), Woods (20del of Rodriguez-Iturbe dynamic soil water sto a99; Laio et al., 2001; Porporato (Rodriguez-lturbe et al., (2001) for a comparison of some of et al., 2004). Sees

these approanes. Based on a theoretical aneloped analytical solutions to balance, Milly (19th) devesenting both event-scale and estimate annual runs, in climate. He tested this method withseasonal variations in fle fata from catchments located out model calibration, for data in the USA. He concluded east of the Rocky Mluctuation of the forcings was always that the seasonal fluctuation of thents, while the effect of relevant, especially in arid catchments holding capacity on local spatial variability of soll wall. By extending Milly's annual runoff was negligibly smal. By exts in the representaapproach to include variable phase shifts in t2005) made estition of seasonal climate, Potter $e$ t al. (2005) made estmates of the water balance of 262 Australin et al. (2005) results are presented in Figure 5.20 . Potter et al. (2005) found satisfactory results except for catchmesised the summer-dominated rainfall, where they hypothesised the infiltration excess was a dominant run

anism, not represented in their model. In their analytical approach, Sankarasubramanian and $\checkmark$ ogel (2002) adopted the abcd model (Alley, 19atle to an alternative to Budyko-type models in or the account for effects of the dynacs derived relationships capable of predicting actuale which ation and the inter-annual variaility of rnsil moisture depended on both the aridity index and arameters. To storage index, related to one of the model parameril moisapply the method to ungauged catchments, the soil mories ture storage index was estimated using monthly time serics of precipitation, potential evaporation and an estimate of maximum soil moisture holding capacity. This is available globally at a 0.5 degree resolution (Dunne and Wimor. 1996).

\subsubsection{Continuous models}

Annual runoff and inter-annual variability Hydrologists now have access to a plethora of con simple precipitation-runoff models. These range from simp 10 single storage models with annual time steps, throug complex theoretically based models with time steps 0

than an hour. To compute a time series of annual runoff in a PUB setting requires a time series of precipitation and relevant forcing variables for the target catchment, along with appropriate model parameters. Assuming that a reasonable predicted time series of runoff output can be obtained from the model, the mean, inter-annual variability and auto-correlation of annual runoff can be computed from the statistics of this time series. Other annual seriesbased analyses include rend analysis (Chiew and McMahon, 1993; Salas, 1993; Milly et al., 2008), runs analysis (Yevjevich, 1967; Saldarriaga and Yevjevich, 1970; Sen, 1976; Hisdal et al., 2001; Peel et al., 2004a, 2005), establishing the probability distribution function of the annual runoff (Vogel and Wilson, 1996; McMahon et al., 2007b) and analysing the time series structure of the data that will allow more sophisticated analysis such as stoch that wil generation to be carried out (Matalas, 1967. Stedinger and Taylor, 1982a, b. Hipel and McLeod, 1994. Thyer et al. 2002).

The difficulty in applying continuous models is twofold: (i) identifying an appropriate model strus is two(ii) obtaining the necessary parameter set(s) that allow an model to produce plausible runoff values Paraw the regionalisation to unguged founded by poor parameter identification at gauged catchments. There are numerous sources of panter uncertainty, including errors in input data, error in model structure and errors of the calibration dat. Even the cho of the objective function and optimistion calibration contribute to uncertainty (see Peel and Blo for 2011. and references therein). These isses Peel als Bloschl, more detail within the PUB framework in Chassed in arc not addressed here. There are few and only limited guidance for objectively assessing model structure for ungauged catchments (e.g., when using lumped conceptual models, more arid catchments generally require more complex models). Once a model structure is chosen, there are many methods for paramete estimation (see Section 10.4). Thus, the benefits of makin high resolution temporal predictions trade off to some extent against the challenges imposed by managing uncertainty in these predictions.

\subsubsection{Proxy data on annual runoff processes}

Tree ring chronology and paleoclimatology

Proxy data allow analysts to extend time series of annual runoff to periods prior to runoff observations. A statictica relationship usually regression, is established between observed runoff and one or more proxy data series, which is then uned to synthesise are proxy data series, which driven by the long proxy records. ture exists where tree ring mate proxy records are used to developer paleoclrelationships with observed annulov satisfactory NOAA Satlite and Information Service (NOAA Pa.eochmatology 2011) lists runoff roconstions (NOA Paleoclirivers, the Selenge River in Mongolia and he Bula River and ofhe Quent in River the Sele of recent the Canadian prairie rivers (Case and Macdonald, 2003),

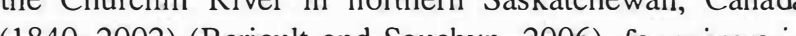
(18402) (Benath River Quensland, Australa (Lough, 2007), the Murray 2011), he Yellow River in wesen China (Gou et al., 
2007) the Manasi River in north-west China (Yuan et al., 2007), the Manasi River in Chile (1590-2000) (Urrutia 2007) and the
et al., 2011).

et al., 2011). All the above techniques arecord. Saito et al. (2008) and runoff to a proxy time series extended this approach by Gray and McCabe (2e water balance model with annua incorporating a simple wata modified to represent annua time series of tree ring data modicabe (2010) incorporprecipitation as input. Grall. The procedure requires further ated temperature as well The prouring.

research but the results are encouraing. (2012) recently Beyond tree ring analys be useful as a proxy showed that vegetation cover elasticity analysis to for annual thnof. The quantify the effects of climate vacing subsurface runoff) partitioning (including total, and vegetation cover (including woody vegetation cover). They cofficient increase with runoff, evaporation and runoffs in which woody vegetavegetation cover for catchming tion is dominant and annual precipia cover may be used as

These results suggest that vegetation cover mearch is needed.
a runoff proxy, but further research

Remote sensing
Despite tremendous promise, remote sensing data do not yet offer reliable means to estimate time series of annum runoff at ungauged sites. Research to estimate annual runoff via remote sensing follows two lines of entimate the first approach, remote sensing is u components of the water balance inted using therm example, evaporation can be estimated using therma methods that relate evaporation to the temperatire difference between soil and vegetation canopies; or though residual energy balance techniques in which to to estimate vations of air and surface temperature are un net radiation and soil heat flux, and a variety of competing schemes then employed to parameterise sente hea fluxes. These techniques are employed by the land surface schemes SEBAL, SEBS and ALEXIDIS-ALEXI (Courat et al., 2005; Bastiaanssen et al., 1998, Anderson and Kustas, 2008). Precipitation can be estimated using satlite radar data (e.g., TRMM), microwave products are available to estimate shallow soll moisture and, at large scales, the GRACE mission can constrain estim esidu storage change. Runoff is then computed as the residua of the water balance. Gao et al. (2010), however, found that closure of the water balance is not currently possib using remote sensing in large catchments. Combining modelling and observations through data assimilation, however, offers an opportunity to reduce modelling errors. In the second approach, remote sensing is used to estimate

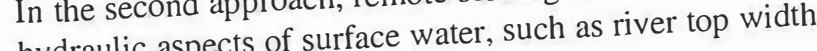

and then compute runoff through the use of a rating curve. Asdorf et al. (2007) reviews progress in this area

Figure 5.21 presents the results from an application of conte obtain distributed estimates of annual runoff across Sri Lanka, taken from Bastiaanssen and Che SEBAL technique f

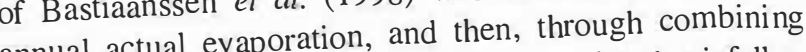
a measured and interpolated rainfall, a hese rainfall minus actual evaporation) rainfall sur (hen partitioned into several large was of monthly runof basin. Fing $5.2 \mathrm{lc}$ presents for two selected iver basined and estimated (based on comparisons between mon folumes for the majority of remote sensing) an the country indicating that there is river basins across the countryat to estimate annual

considerable potentiver basins.

\subsection{Comparative assessmen}

The aim of the comparative assessment of annual runof The aim of the com the lam predictions in ungares between catchments in differen thes and differences in performance places, and to underlying climate-landscape control terms of the controls sheds light on the nature of Understanding these constems and provides guidance on catchments as complex sy what methods to che ta tevels (see Section 2.4.3). assessment is performent is a meta-analysis of studies The Level 1 assessm. The Level 2 assessment involves reported in the literature. The alysis of individual basins a more focused and detailed analysis 1 in terms of how the from selected studies of Lever and catchment characterperformance depends on chimed chosen. In Level 1 and istics as well as on the was evaluated by Level 2 assessments, the performance was eves of fitted leave-one-out cross-validation (or just goodults were no regressions where the cross-alidation s-validation each available). In the leave-one-out cond the runoff predic catchment was treated as ungauged and the runoff. The tions were then compared to the obsetve assessment an performances obtained by the comparive predictions in estimates of the total these ungauged basins.

\subsubsection{Level 1 assessment}

1.

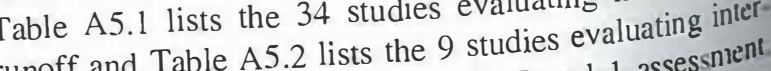

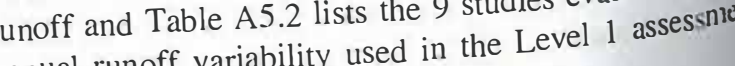
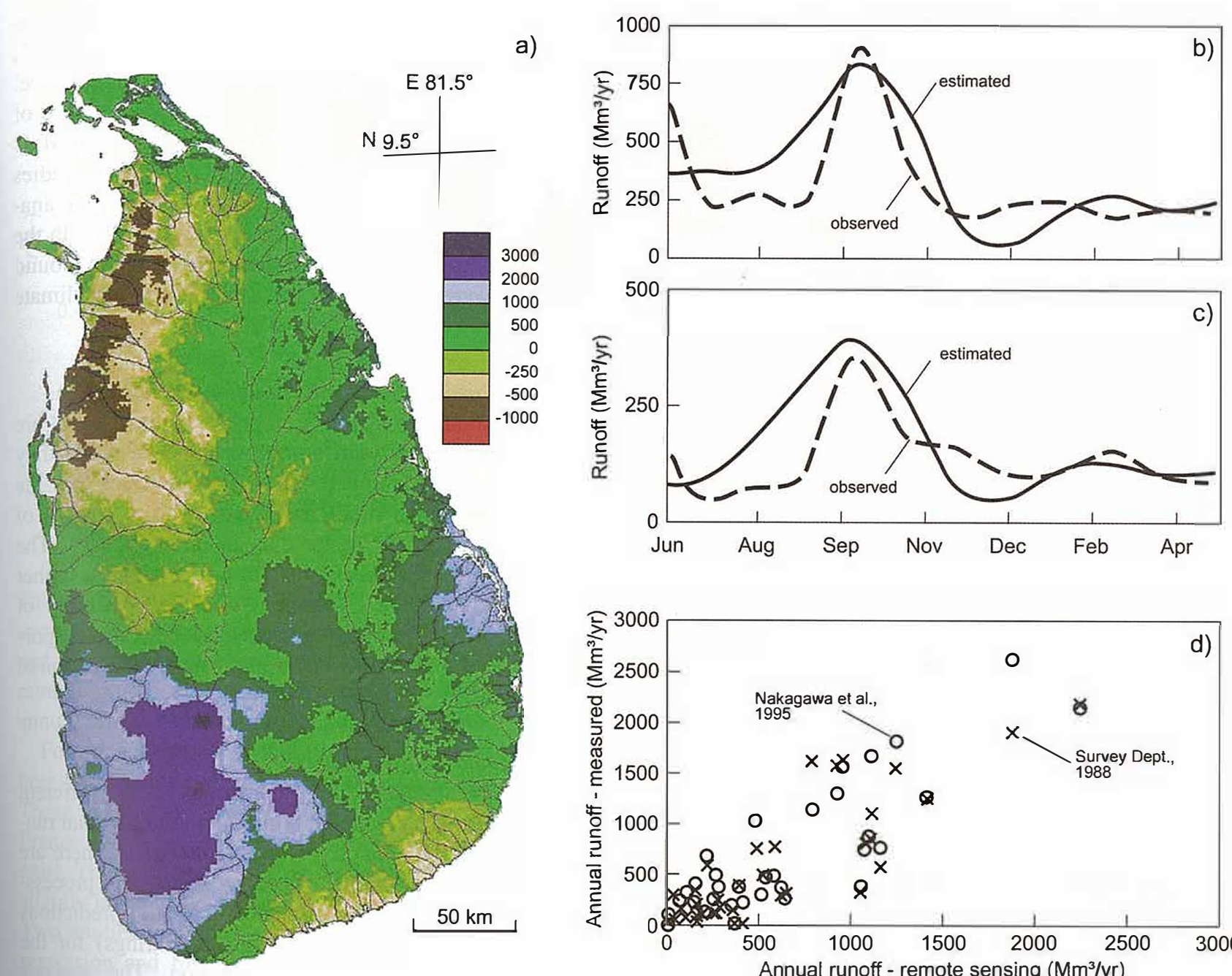

Jun Aug Sep Nov Dec Feb Apr

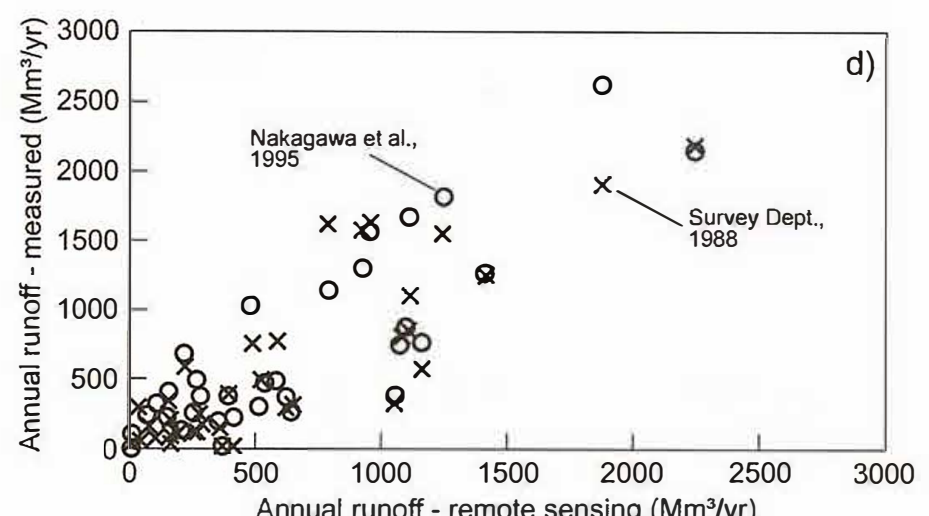

Annual runoff - remote sensing $\left(\mathrm{Mm}^{3} / \mathrm{yr}\right)$

Figure 5.21. (a) Rainfall surplus (gross rainfall minus actual evaporation) between June 1999 and April 2000 across Sri Lanka, with the river basin boundaries superimposed; (b) observed and remote sensing predicted runoff for Kelani Ganga and Gin Ganga, two major rivers in Sri From Bastiaanssen and Chandrapala (2003).

Many of these studies are based on large data sets providing a broad range of results from catchments in different climates. The number of catchments the studies evalun ranges from 1 in local studies to more than 1000 in global studies. There are several studies that compare different regionalisation approaches, which rests in a total of 41 and 19 results for predictive performts in annual runoff and inter-annual variaility, respective The regionalisation methods used ab regression, in methods, spatial proximity, pred as methods using proxy ty used in the assessment is the squard correlation cient, $r^{2}$, between predicted and observed mes coeffiunoff and between predicted and ceviation of annual runoff. It is important to note that performance values presented in Tables A5.1 and A5.2 differ greatly depending on whether they are reported as specific mean annual runoff (in $\mathrm{mm}$ ) or as volumetric runoff $\left(\right.$ in $\mathrm{m}^{3}$ ). Performance values tend to be much higher when annual runoff is expressed in volumetric units (i.e., in $\mathrm{m}^{3}$ ) since they include the effect of catchment area, which is always a strong predictor of runof volume. In the figures that follow, this distinction is highlighted by displaying the performance values based on volumetric units as crosses and those based on specific runoff as circles. For comparison with the othe 政 were calculated for all methods in all studies with the these ${ }^{2}$ are 0.65 and 0.91 , respectively. 


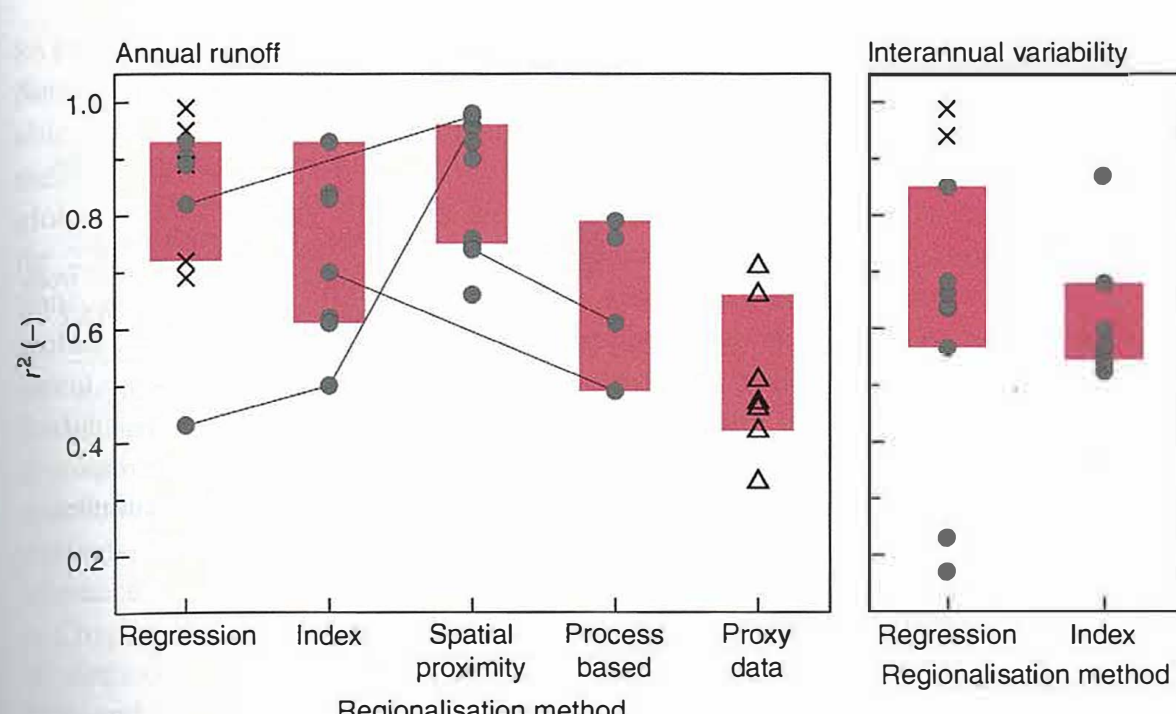

Figure 5.24. Squared correlation coefficient $\left(r^{2}\right)$ of predicting annual (right) ient) and inter-annual runoff (right) in ungauged basins stratified by regionalisation method. Each symbol refers to a result from the studies shown in Table A5.1 (annual
runoff) and Table A52 (inter-annual runoff) and Table A5.2 (inter-ann compared different methods for the same set of catchments. Boxes show $25 \%-75 \%$ quantiles. mate classification of Peel et al. (2007). The following classification criteria were applied. Altreshold value are classified as belonging to the B climate in Peel et al. (2007) and as 'arid' in this assessment. If $70 \%$ of the mean annu precipitation occurs in winter, the threshold (in $\mathrm{mm}$ ) is 20 times the mean annual temperature (in degrees Celsius). $70 \%$ of the mean annual precipitation occurs in summe the threshold is 20 times the mean annual tempan annua 28. Otherwise the threshold is 20 times the mean annit temperature +14 . For areas where mean annal precipitation exceeds the threshold, other climate types are possible. In this assessment, the locations where the temperature of the coldest month is not lower 'tropical' (A climate in Peel et al., 2007). The locations where the temperature of the hottest month is above $10^{\circ} \mathrm{C}$ and the temperature of the coldest monh is between 0 and $18^{\circ} \mathrm{C}$ are defined as 'humid' ( $\mathrm{C}$ climate in Peel et al.

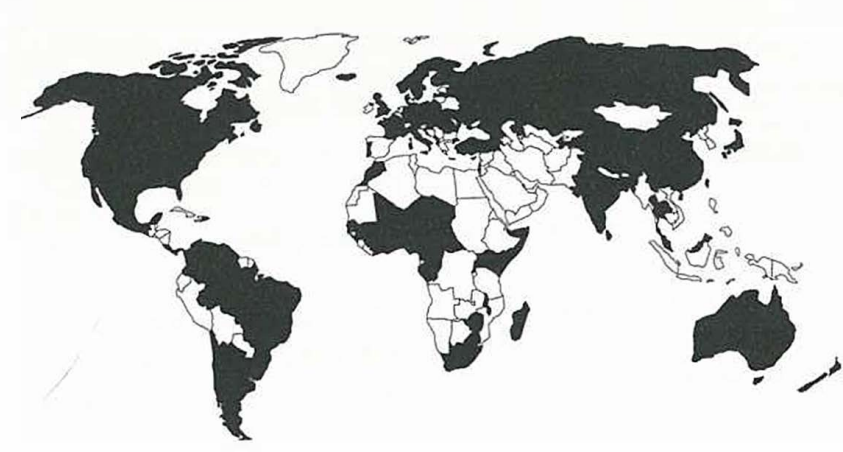
Figure 5.22.
assessment.

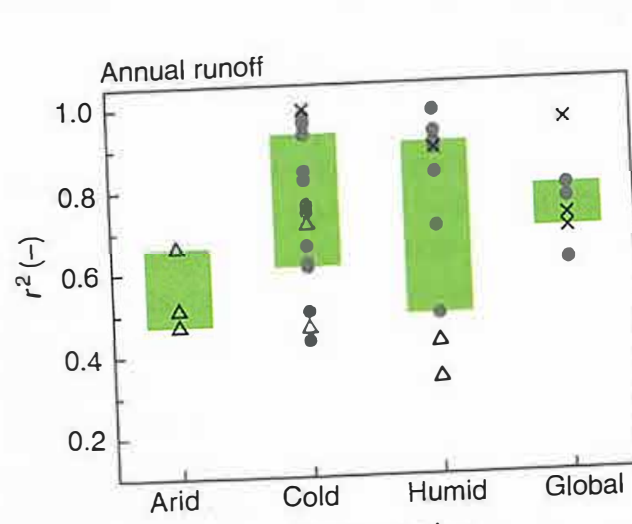

Climate region
Interannual variability

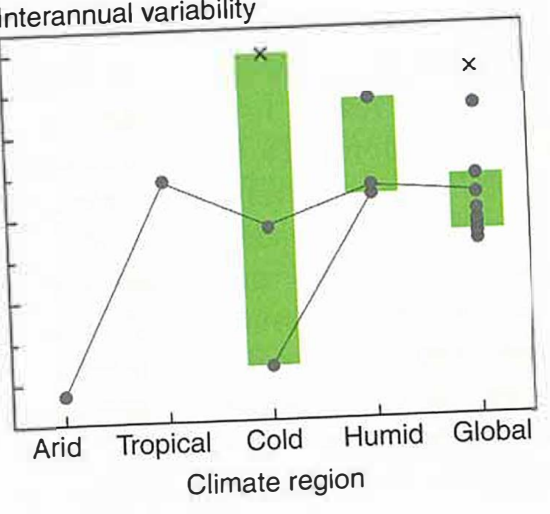

Figure 5.23. Squared comelation coefficient $\left(r^{2}\right)$ of predicting annual runoff (left) and inter-annual runo (right) in ungauged basins striti nosy from the studies shown in Table AS. (annual runoff) and Table A5.? (inter annual runoff). Triangles inditat bace temporal variablity assessmestes sudies on tree rings. Line method was applich
where the same where the sement climate regiolis. Boxes show $25 \%-75 \%$ quantile
These are all interpolation methods including geostatistical These a Process-based models are ondy geostatistical approaches. Pocess-based models are only rarely applied and are represented here by four results that used different
rainfall-runoff models. Finally, eight results that estimate annual runoff based on proxy data are available. For annual runoff, spatial proximity methods show the These results are mainly from north-eastern USA and France wher a considerbe number of strem gauges exis. The performance of regression methods tends to be slighly lower. The studies com from a mix of continents. Two studies in Europe compared spatial proxinty with Two studes in Eure com spatial proximity. In regions where annul runoff vares spatial prox thy stem gures exist, it is not suprising that sparat proxstream galses exist, it is no supising that spatial proxthat some of the results for the . session also be based on volumetric runoff value (crosses in Figure 5.24) so, if only specific runoff is considered, performance is actully lower is considered, the median

in fact as well (such as Budyko) also perform quite well, some of the regression results re for von, considering that performance of process-based methe models) tends to be lower, with a Clearly. the performance wrongly depends on the way the models are calibrated to existing de ness, methods that use tree ring (proxy) data but, not surprisingly, suggest haxy) dat For core included choronology is to reconger han to predict runoff in the prest runff variabihy rather For the prediction the present climate.

rgression and index methods peffor median $r^{2}$ of 0.65 and 0.57 respectively. The results of the regression method have a much larger scatter. In general, the performance is somewhat lower than the perform ance obtained for men anul runoff since, clearly, interannual variability is harder to predict.

How does data availability impact performance?

Figure 5.25 shows the predictive performance as a function of the number of catchments analysed in each study. Most of the studies used relatively large data sets, although this probably reflects the fact that most studies evaluate the accuracy of predictions in space. An exception is the prediction of temporal variability by proxy methods (i.e. tree rings), which is usually tested only on single catchments.

The results indicate that the performance does not seem to depend on the size of the data set. Apparently, on seen from a small huber of gauged catch order to predict mern onnual runoff within the study ar in ungauged bains. There may be two effects retar to scale. The first is that he total heterogeneity tends to increase as he size if a region increses, which would be expected to lower the performe if the same method is used in the entire region. The second is that, with increasing in the size, the methods may be adjusted more reliably to the existing un the two effects may coun to each other as the size of the data set increases. The predicion of inter-annua unoff varibility, on the other hand more specific and improves with the availability of arger data sets.

More detailed insight into the dependency of performance on both method and number of catchments per study s shown in Figure 5.26. Index-based methods have been evalut 


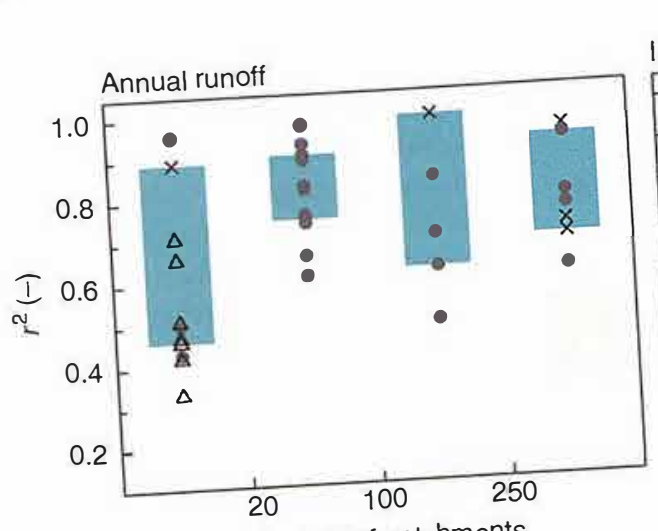

Number of catchments

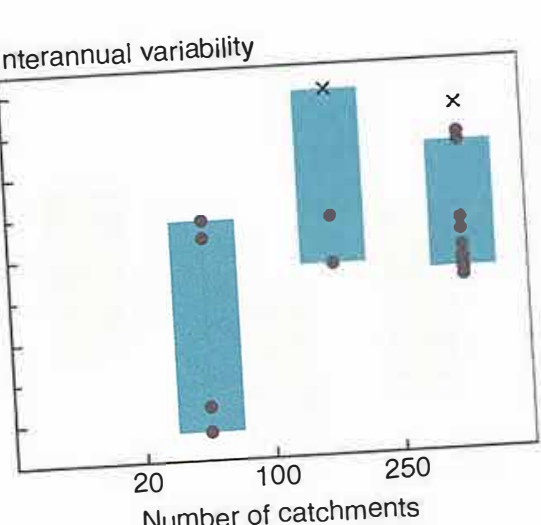

Number of catchments
Figure 5.25. Squared correlation coefficient $\left(r^{2}\right)$ of predicting ann unoff (lett) and inter-anntal runoff (right) in ungauged bs stratified by the nin Each symbol refers to a result from the studies shown in Table A5. (annual runoff) and Table As.2 indicate the temporal variability assessment based on tree rings. Boxes show $25 \%-75 \%$ quantiles
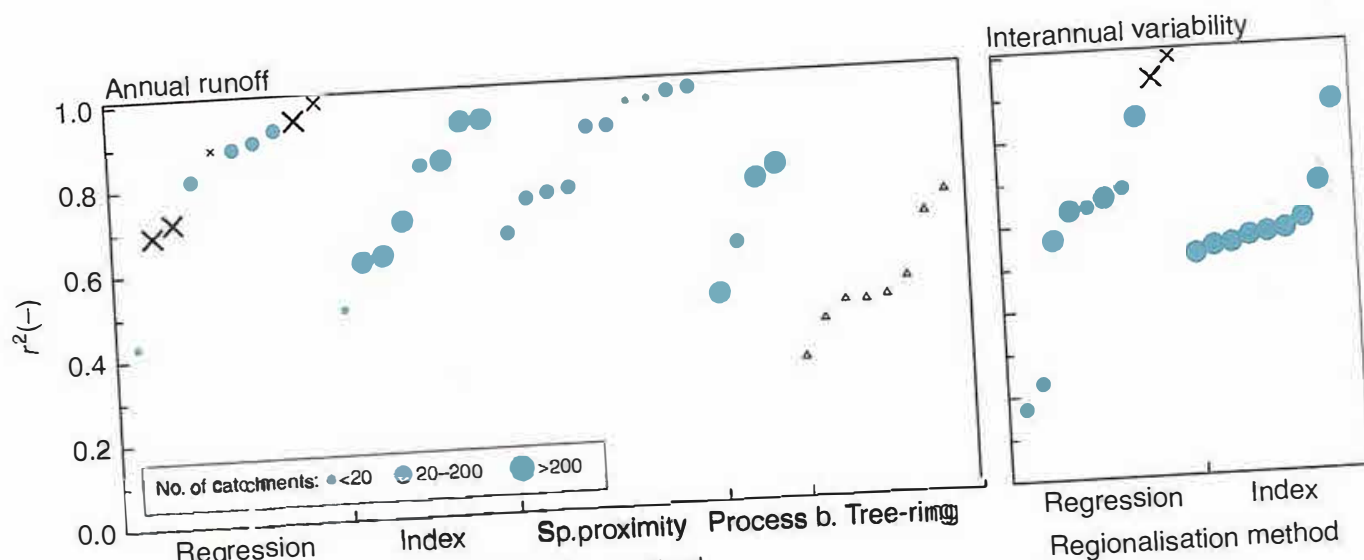

Regionalisation method

Regionalisation method

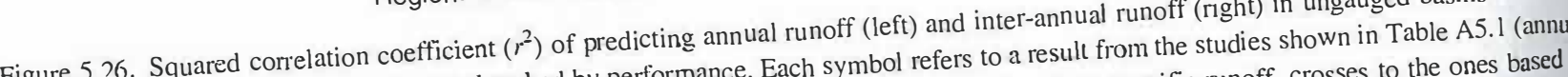
Figure 5.26. Squed and ranked by performance. Each sybol stratified by the regionalis
runofff and Table A5.2 (inter-annual runoff). Circles refer to the performance

The have been mainly tested for data sets with more strongly catchments. The type of methed seember of catchments per control the

study.

The conpaison between regression and index methods The comparison between regressity indicates that the for inter-annal runoff vary similar data set sizes methods have been tested

\section{Main findings of Level 1 assessment}

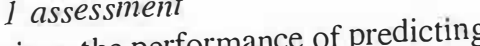
- In cold and humid regions the performance of predicting the mean and variability of annual runoff in ung

basins tends to be better than in other climates.

- Methods based on spatial proximity perform best, followed by in

form similarly.

- At the scale of the analyssed methods available for the performance of the processed seems to be essential.

- Pretion de not dene Predictions of mean in the study, while predictions of number of catchments in the study, with the number or annual runof $v$
catchments.

5.5.2 Level 2 assessment clearly showed that many studies only report summmant statistics of regionalisation performance and/or catchmem characteristics, which hampers detailed attribution of the performance and inter-study comparison of results. objective of the Level 2 synthesis is to examine objective of erformance of the regionalisation methood the explain the performance 2 assessment is based on the global data set of Peel et al. (2010) that provided detist in information about climate and catchment characteristick information about climater anted the regionalisation perfor from ance for each catchment. This data set combines da fr
861 catchments located in 82 countries around the world No data for the inter-annual runoff variability were available, so the Level 2 assessment presents only results for mean annual runoff. In order to identify differences in global and local scale analysis an additional assessmen for 220 catchmo in Austia was also performed (Viglione et al., 2013b). Based on the data availability an global coverage, three approaches were applied: two statistical approaches, global and regional regression, and Budyko index model. The normalised error (NE) and the absolute normalised error (ANE) were used as performance indicators (Table 2.2). The NE highlights biases in the methods, while the ANE is a measure of the overall performance. For comparison with the other runoff signatures in Chapter 12, the $r^{2}$ of annual runoff were calculated for all methods of both the global and the Austrian data. The $25 \%$ and $75 \%$ quantiles of these $r^{2}$ are 0.52 and 0.81 respectively.

Performance measures are presented in the followin figures as a function of the aridity index, mean annual a temperature, mean elevation and catchment area. Note tha the ANE is an error measure, so it has been plotted downwards on the vertical axis to make it comparable with the performance measures, i.e., higher up in the plot is better.

To what extent does runoffprediction performance depend on climate and catchment characteristics?

Before analysing the NE and ANE of the three chosen approaches, a regression analysis of mean annual runoff with area, mean annual precipitation and mean annua remperature $\left(T_{\mathrm{A}}\right)$ was performed in order to understan which predictors are important for mean annual runof under different climatic conditions. The $r^{2}$-value, calculated based on specific runoff, did not exceed 0.5 for any of the regressions. This indicates that the size of catchments and global climate variability control only part of mean annual runoff patterns. While all three predictor were significant for estimating mean annual runoff in humid, cold and arid conditions, the analysis showed the for tropical climates $T_{\mathrm{A}}$ does not play any role.

The ANE error measure of mean annual runoff with respect to the four climate and catchment characteristics is presented in Figure 5.27. The results clearly indicate the the performance of all models decreases with increasing andity (top panel). For global regression and region egression the median ANE is around 0.2 for humid ents and 1 or larger for arid catchments. For the Budyko pproach, the errors in the aridcatch or the other methods. Apparently the structure of Budyko is more suited to predicting mean anuat and catchments than regressions. The regresion models and to overestimate mean annual run off in arid Fure 5.28), while Budyko gerilly nderestimate mean annual runoff. It should be noted that the Budyko relationship was not calibrated but the regression coefficients were. The dependence of ANE on air temperature shows a similar, but less pronounced pattern. This means the difficult climates to predict are the arid catchments and not necessarily the catchments with a warm climate.

A clear relationship does not seem to exist between ANE and catchment area. For regression models, the variability of ANE performance between catchments of the same size is larger than for the Budyko model. This variability is the largest for catchments larger than 1000 $\mathrm{km}^{2}$. The Budyko model seems to be a robust method. Even though there is a tendency for underestimating runoff, the results are more consistent for a given catchment size.

Which method performs best?

Figure 5.29 summarises the performance for different regionalisation approaches, stratified by the aridity index. The top, middle and bottom panels show the performance for all catchments, and catchments with an aridity index below and above 1, respectively. Overall the Budyko model performs better than the two regression approaches. Regional regressions perform better than global regression. While the performance in humid catchments is quite similar for all three approaches, in arid regions the performance of the Budyko approach is much better than that of regressions. The built-in principle of water versus energy competition included in the Budyko model appears to provide an inherent advantage for mean annual runoff prediction compared to purely statistical approaches, particularly in arid regions. It should also be noted that in arid regions the regional regressions perform significantly better than global regressions, while this is not the case in humid regions.

Global scale results vs. local scale results

The results of the Level 2 assessments compared the performance of statistical and index methods on a global scale. The performance of methods for mean annul runoff prediction in a particular region depends on the hydrological variability, as well as data availability an example, Figure 5.30 compares different approas for mean an for for mean annual runoff prediction in 220 catchments humid with the aridity index renging from 0.2 to 1.4 The following methods were used: the globs 0.2 to 1.4 model fitted to the gobal dase the global regressio using calch to the global dase set of pele al (2010) using catchment area, mean annual precipitation and a approch; a as ceron segression model filed to the Austhin tha (using the same cotch

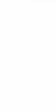




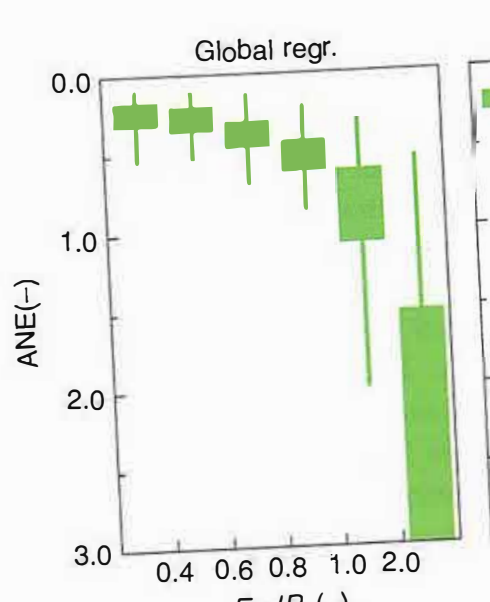

Regional regr.

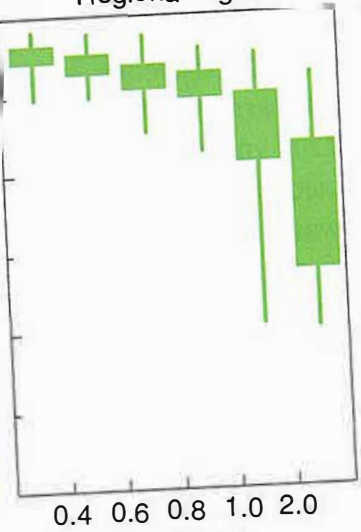

$E_{\mathrm{PA}} / P_{\mathrm{A}}(-)$

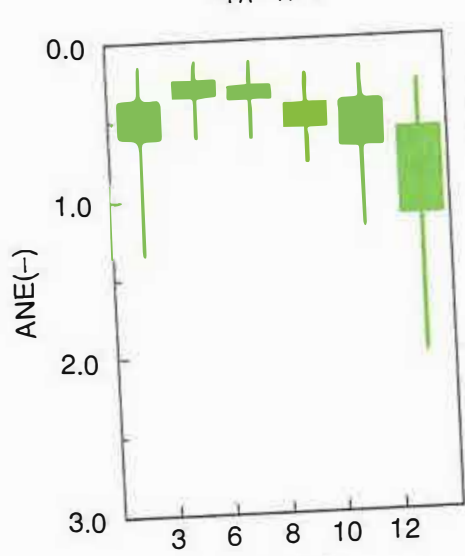

$\left.T_{A}{ }^{\circ} \mathrm{C}\right)$

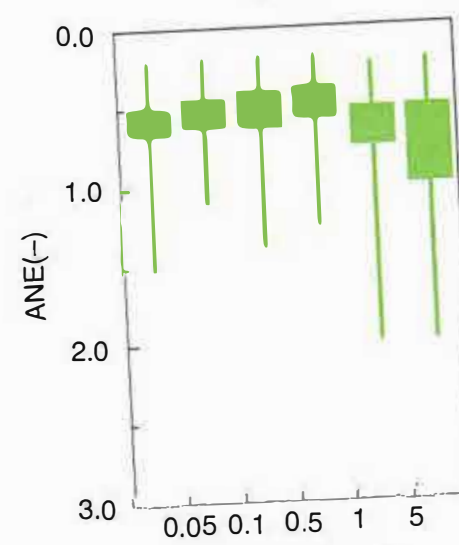

Area $\left(10^{3} \mathrm{~km}^{2}\right)$
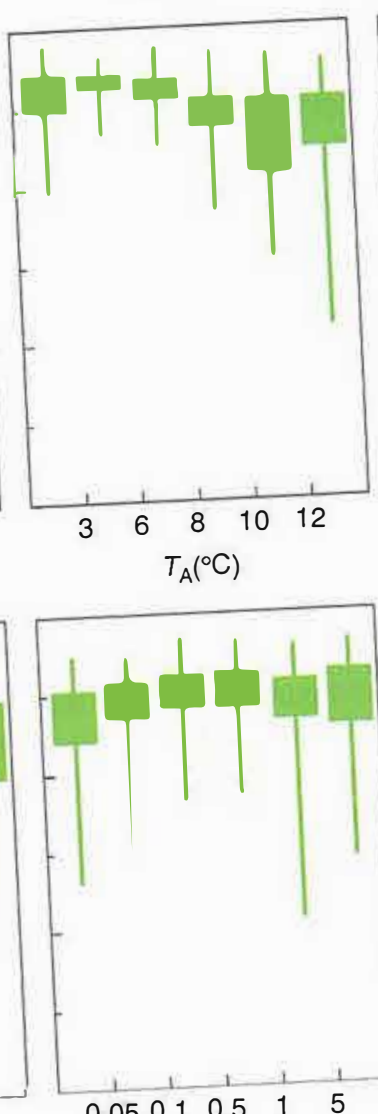

Area $\left(10^{3} \mathrm{~km}^{2}\right)$
Budyko

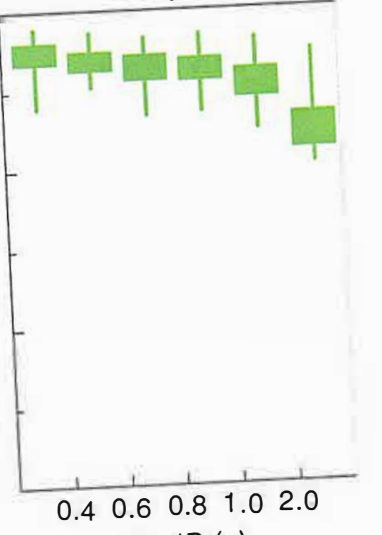

$E_{\mathrm{PA}} / P_{\mathrm{A}}(-)$
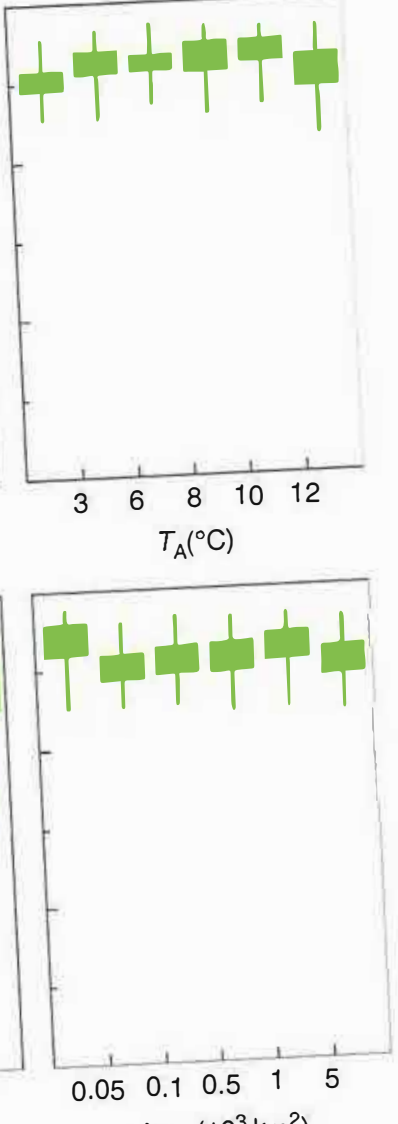

Area $\left(10^{3} \mathrm{~km}^{2}\right)$
Figure 5.27. Absolute normalised function of aridity $\left(E_{\mathrm{PA}} / P_{\mathrm{A}}\right)$, mean annual air tenpera different methods. catchment area for dir Boxes are $40 \% 60 \%$ q quntiles. runoff in ungauged basins as a

for the global regression: catchment area, mean annual precipitation and air temperature); a process-based (conceptual soil moisture accounting model at the daily tim scale); and a geostatistical method (top-kriging). Overall the performance is much better than that of the global predictions as one would expect given the higher data predictiol as The global regression model gives ANE around 0.3 as opposed to 0.4 for all humid catchments of the Level 2 assessment (Figure 5.29) indicating that the Austrian data set is in a range where the regression model works well. The Budyko model and the regional regressions perform better than the global regressions: Note, again, that Budyko was not calibrated to the dhe trian data, while the regional regressions were.
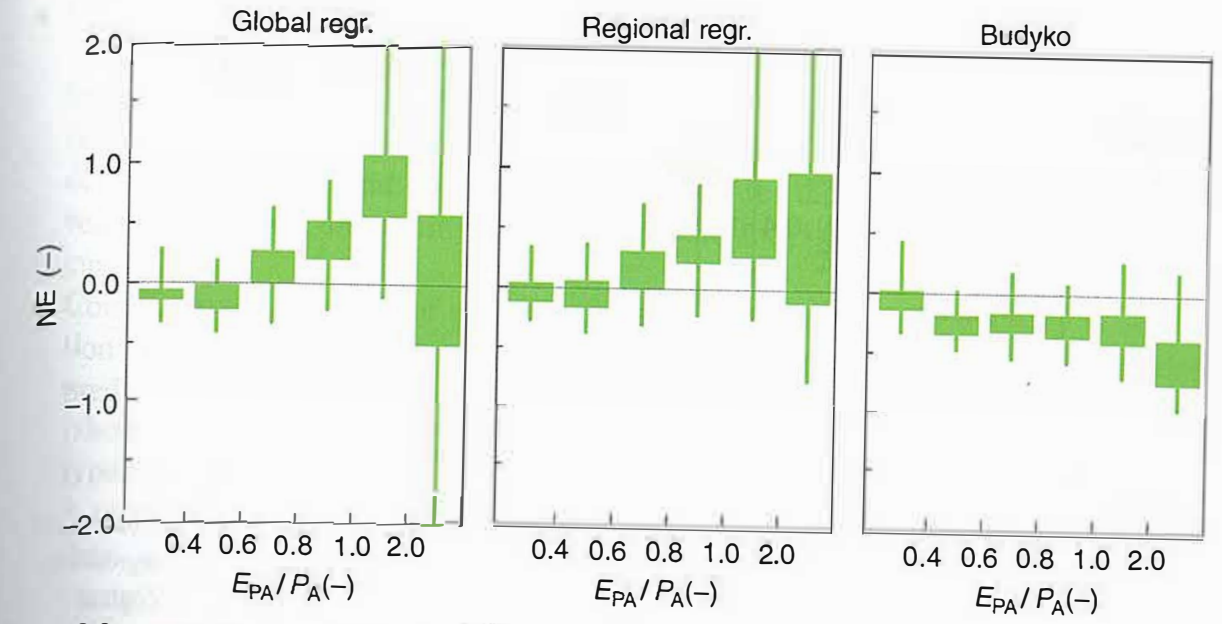

Figure 5.28. Normalised error (NE) of predicting annual runoff in aridity $\left(E_{\mathrm{PA}} / P_{\mathrm{A}}\right)$, mean annual air temperature $\left(T_{\mathrm{A}}\right)$ and catchment are for different methods. Boxes are $40 \%-60 \%$ quantiles, whiskers are $20 \%-80 \%$ quantiles.
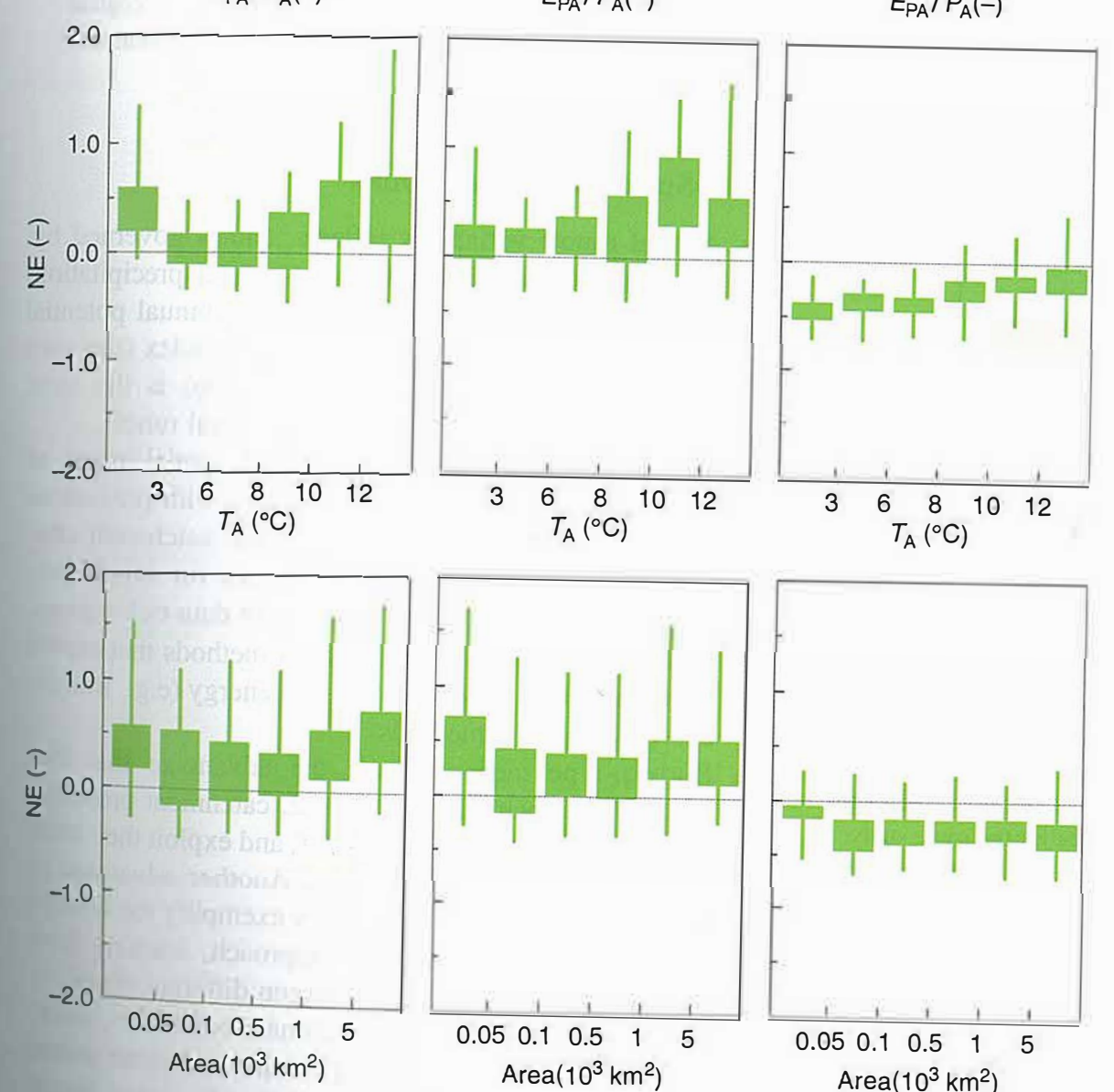

Area $\left(10^{3} \mathrm{~km}^{2}\right)$

Area $\left(10^{3} \mathrm{~km}^{2}\right)$

process-based approach and geostatistics perform best in predicting mean annual runoff in ungauged basins. This indicates that the use of regional data can improve the predictions significantly beyond global methods. The model. wh point towards the strength of the Budyko model, which is very good even though it was not
calbrated.

Main findings of Level 2 assessment

- The performance of all methods of predicting mean annual runoff in ungauged basins decreases with increasing aridity

- There is a tendency for the performance of the regression methods to decrease with air temperature but no apparent dependence on catchment size. 


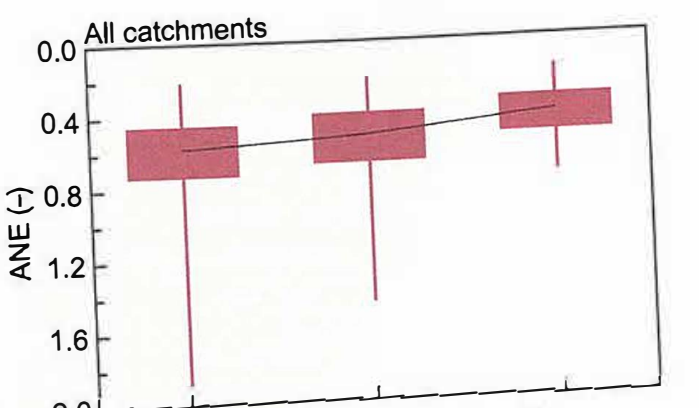

0.0 Humid catchments (aridity index $<1$ )

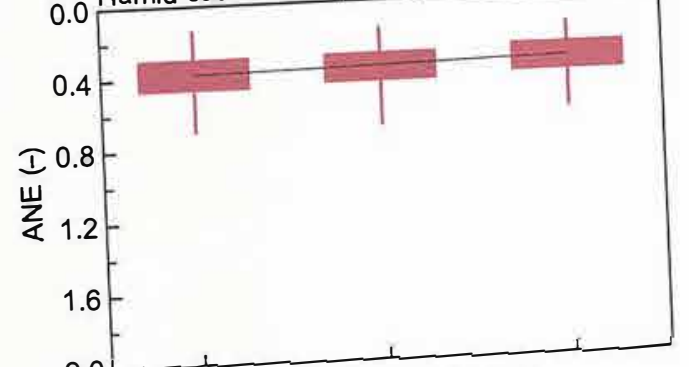

0.0 Arid catchments (aridity index $\geq 1$ )

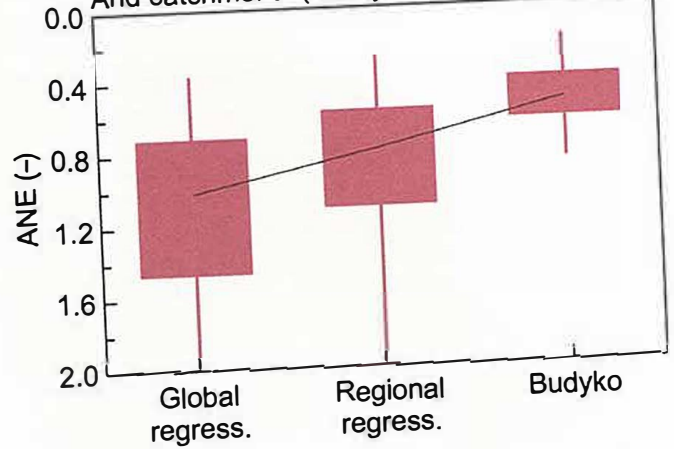

Figure 5.29. Absolute normalised error (ANE) of predicting me annual runoff in ungauged basins for All catchments; (centre) humid methods, stratified by aridity. (Top) Alr arid catchments (aridity catchments (aridity index $\geq 1$ ). $40 \%-60 \%$ quantiles, whiskers are $20 \%-80 \%$ quantiles.

- The Budyko approach tends to underestimate mean annual runoff. The mate runoff in arid catchments.

In humid catchments, the Budyko approach and regression methods perform similarly.

In arid catchments, the Budyko approach performs mu better than the regression methods. Regio regressions perform better than global regression.

- In a regional case study, the performance of predicting mean annual runoff in ungauged basins for different methods increases in the following order: global regres sion, Budyko model, regional regression, process-based method and geostatistical approach.
- Process-based methods, especially those that belong to the derived distribution category, can assist in interpreting the process basis of the index-based relationships (e.g., Budyko), help understand their applicability to different situations, and can explain the reasons for the scatter (and hence uncertainty) around the mean Budyk curve.

- Comparative assessment of all methods used for prediction of annual runoff in ungauged basins indicated tha predictive performance decreases with increasing aridity (shown in both Level 1 and 2 assessments). Budykotype index methods perform better in arid regions (Level 2 assessment) compared to regression approaches, they are built around the principle of water versu energy competition. Spatial proximity methods (e.g. geostatistics) outperform other techniques (Level 1 and
2 assessments). They require stream gauges in the region of interest.

Annual runoff variability represents the foundation (i.e., low frequency variation) on which all other runoff variability is built. Understanding annual runoff variability is the key to understanding the remainder of the variability found in the runoff hydrograph. Annual runoff variability is also the signature that best reflects the coevolution of climate, soils, vegetation and topography. Therefore, there is much to be gained from understanding the nature of annual runoff variability and how it connects to vegetation, drainage density and other patterns, which are all a result of the same co-evolutionary processes. Comparative hydrology represents a clear way forward for the joint investigation of these coevolutionary patterns across different parts of the world. . estimated by global regression, Budyko model, regional regressiol (fited to Austian data), process-based (concoph in 209 humid model) and geostatisticu (r.

\subsection{Summary of key points}

- Annual runoff variability reflects, and is governed by, he relative availability of water (annual precipitation) and energy (expressed in terms of the annual potential evaporation). Consequently, he anidy index (he ratio of potential evaporation to precipitation) is the most widely used similarity measure for a

- Increasingly, traditional interpolated spatial maps of mean annual runoff are being replaced wih prent atribased on regressions with climate and cat butes (as predictors and as surrogates for ich cesses), geostatistical interpolations in data-tich rego and the application of index-based methods thexplo the competition between water and engy (e.g. Buplo curve and related methods).

Budyko-type methods have the advantage that the reflect the co-variation of climate, calchment propertes (including vegetation) and runoff, and exploit their ine relationships in a holistic way. Another advantage of Budyko-type methods is that they exemplify the benefit of a comparative hydrology approach, leaming for similarities and differences between different places. - Under humid, arid and cold climate conditions, catchment area, mean annual temperature and mean an precipitation are important predictors for mean annual runoff in the regression approach (with the exception of tropical climates where mean annual temperature does not have much predictive power). This reflects the capacity of these predictors to capture the combined effects of several process controls on annual tunor Co-evolutionary indices that are reflective of annual runoff variability are drainage density and vegetation paterns (fraction of vegetation cover, as well fractions of deep-rooted trees and shrubs). 


\section{University Library}

\section{- M I N E R VA}

\section{A gateway to Melbourne's research publications}

Minerva Access is the Institutional Repository of The University of Melbourne

Author/s:

McMahon, TA;Laaha, G;Parajka, J;Peel, MC;Savenije, HHG;Sivapalan, M;Szolgay,

J;Thompson, SE;Viglione, A;Woods, RA;Yang, D

Title:

Prediction of annual runoff in ungauged basins

Date:

2013-04-18

\section{Citation:}

McMahon, T. A., Laaha, G., Parajka, J., Peel, M. C., Savenije, H. H. G., Sivapalan, M., Szolgay, J., Thompson, S. E., Viglione, A., Woods, R. A. \& Yang, D. (2013). Prediction of annual runoff in ungauged basins. Bloschl, $G$ (Ed.). Sivapalan, M (Ed.). Wagener, T (Ed.). Viglione, A (Ed.). Savenije, H (Ed.). Runoff Prediction in Ungauged Basins, (1), pp.70-101. Cambridge University Press.

Persistent Link:

http://hdl.handle.net/11343/33183 